\title{
The Economic Effects of Trade Policy Uncertainty
}

Caldara, Dario, Matteo lacoviello, Patrick Molligo, Andrea Prestipino, and Andrea Raffo

Please cite paper as:

Caldara, Dario, Matteo lacoviello, Patrick Molligo, Andrea

Prestipino, and Andrea Raffo (2019). The Economic Effects of

Trade Policy Uncertainty. International Finance Discussion

Papers 1256.

https://doi.org/10.17016/IFDP.2019.1256

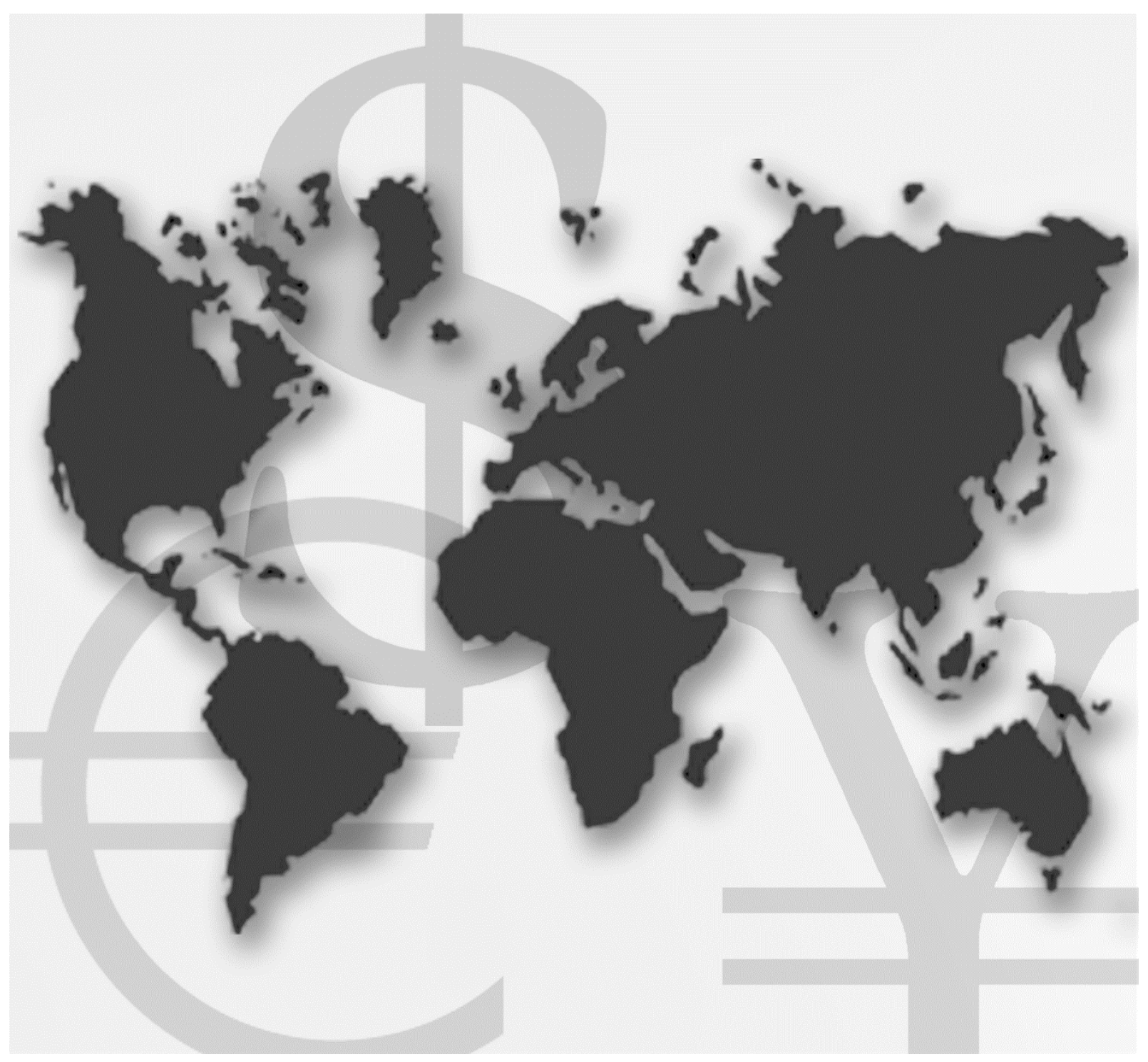

\section{International Finance Discussion Papers}

Board of Governors of the Federal Reserve System

Number 1256

September 2019 
Board of Governors of the Federal Reserve System

International Finance Discussion Papers

Number 1256

September 2019

\section{The Economic Effects of Trade Policy Uncertainty}

Dario Caldara, Matteo Iacoviello, Patrick Molligo, Andrea Prestipino, and Andrea Raffo

NOTE: International Finance Discussion Papers are preliminary materials circulated to stimulate discussion and critical comment. References to International Finance Discussion Papers (other than an acknowledgment that the writer has had access to unpublished material) should be cleared with the author or authors. Recent IFDPs are available on the Web at www.federalreserve.gov/pubs/ifdp/. This paper can be downloaded without charge from the Social Science Research Network electronic library at www.ssrn.com. 


\title{
The Economic Effects of Trade Policy Uncertainty*
}

\author{
Dario Caldara Matteo Iacoviello Patrick Molligo \\ Andrea Prestipino Andrea Raffo
}

August 30, 2019

\begin{abstract}
We study the effects of unexpected changes in trade policy uncertainty (TPU) on the U.S. economy. We construct three measures of TPU based on newspaper coverage, firms' earnings conference calls, and aggregate data on tariff rates. We document that increases in $T P U$ reduce investment and activity using both firm-level and aggregate macroeconomic data. We interpret the empirical results through the lens of a two-country general equilibrium model with nominal rigidities and firms' export participation decisions. In the model as in the data, news and increased uncertainty about higher future tariffs reduce investment and activity.
\end{abstract}

KEYWORDS: Trade Policy Uncertainty; Textual Analysis; Tariffs; Investment; Uncertainty Shocks.

JEL CLASSIFICATION: C1. D22. D80. E12. E32. F13. H32.

Latest version at https://www2.bc.edu/matteo-iacoviello/research_files/TPU_PAPER.pdf

\footnotetext{
${ }^{*}$ We thank the organizers of the Carnegie-Rochester-NYU Conference on Public Policy, our discussant Joseph Steinberg as well as George Alessandria, Aaron Flaaen, Beth Anne Wilson, and seminar and conference participants in various venues. All errors and omissions are our own responsibility. The views expressed in this paper are solely the responsibility of the authors and should not be interpreted as reflecting the views of the Board of Governors of the Federal Reserve System or of anyone else associated with the Federal Reserve System. At the time of writing, all authors worked at the Federal Reserve Board. Data and codes for this paper can be found at https://www2.bc . edu/matteo-iacoviello/research.htm. Corresponding author: Matteo Iacoviello (matteo.iacoviello@frb.gov)
} 


\section{Introduction}

Trade negotiations and proposals for a new approach to trade policy have become the focus of increased attention among investors, politicians, and market participants. These developments have resulted in an increase in uncertainty about the outlook for global trade. For example, in January 2019, the Federal Reserve's Beige Book, a document that compiles anecdotal descriptions of economic conditions in the twelve Federal Reserve districts, contained several references-based on surveys of manufacturers, business contacts, and industry representatives - to uncertainty about the outlook for trade policy.

For decades prior to these trade developments, there was limited volatility in trade policy, and thus limited study of the impact of uncertainty regarding trade policy on the economy. This paper takes a comprehensive approach to fill that gap - developing measures of uncertainty at both the firm and aggregate levels, estimating the effects of these measures on investment, and then interpreting these effects through the lens of a two-country general equilibrium model with heterogenous firms. ${ }^{1}$

In the first part of the paper, we empirically measure trade policy uncertainty $(T P U)$ and its effects. We build a firm-level measure of $T P U$ and link it to Compustat firm-level investment data. We show that increases in TPU predict lower capital accumulation after one year. We then construct two aggregate $T P U$ indicators for the U.S. economy using newspaper coverage and data on volatility of import tariffs. We include these indicators in a VAR model and find that increases in trade policy uncertainty reduce investment and, more generally, economic activity.

The results from the firm-level and aggregate time series analysis predict roughly similar effects of unexpected increases in trade policy uncertainty on investment. Specifically, we find that a shock that is sized to capture the rise in trade policy uncertainty between 2017 and 2018 predicts a decline in the level of aggregate investment of between 1 and 2 percent. Moreover, such predictions are in line with recent survey evidence that directly asks firms how they reassessed capital expenditure plans in response to higher trade uncertainty. ${ }^{2}$

In the second part of the paper we use a two-country general equilibrium model with nominal rigidities and firms' export decisions to understand the channels by which changes in trade policy uncertainty affect investment and economic activity. ${ }^{3}$ In our benchmark experiment, we consider a surprise increase in both expected future tariffs and uncertainty about future tariffs that is sized to match the trade developments observed in 2018. We find that both news - first moment shocks - and increased uncertainty — second moment shocks - about future tariffs reduce investment and output, as in the data. Quantitatively, news about higher future tariffs accounts for a larger fraction of

\footnotetext{
${ }^{1}$ There are important exceptions, of course, mostly focusing on other episodes of trade uncertainty. For instance, Handley and Limão (2017) estimate and quantify the impact of trade policy on China's export boom to the United States following its 2001 WTO accession, and Crowley, Meng, and Song (2018). Steinberg (2019) study the effects of trade uncertainty associated with the Brexit referendum.

${ }^{2}$ See the Survey of Business Uncertainty run by the Federal Reserve Bank of Atalanta (Altig et al., 2019).

${ }^{3}$ Our modeling of export decisions follows the work of Alessandria and Choi (2007).
} 
the decline in macroeconomic variables (i.e. about two thirds) as it directly entails expectations for higher costs of imports and lower demand for exports (i.e. anticipated first-moment shocks). Higher uncertainty about tariffs also dampens investment and GDP by reducing firm entry into the export market and by triggering upward pricing bias for firms subject to price rigidity, which increases markups and reduces hours worked and output.

Our paper builds on the work of several authors that have studied, empirically and theoretically, the macroeconomic effects of uncertainty and uncertainty about trade. On the empirical side, we build on the insights of Hassan et al. (2017), Baker, Bloom, and Davis (2016), and FernandezVillaverde et al. (2015), and apply their ideas to the measurement of trade uncertainty and the understanding of its effects. We do so through a comprehensive approach that studies the effects of trade uncertainty both at the micro-level - exploiting heterogeneity across firms in their exposure to trade risk - and at the macro level-using measures of trade uncertainty based on newspaper searches and on stochastic volatility models. On the theoretical side, our work follows Handley and Limão (2017) and Crowley, Meng, and Song (2018), who study the impact of trade policy on China's export boom to the United States following its 2001 WTO accession, and Steinberg (2019), who studies trade uncertainty following Brexit. Unlike these papers, ours is the first to jointly investigate and quantify the effects of both first and second moment shocks to trade policy in a New Keynesian DSGE model. We find that the presence of nominal rigidities is key for the transmission of uncertainty shocks both directly, through the precautionary increase in markups stressed in Fernandez-Villaverde et al. (2015), and indirectly, through the interaction between sticky prices and wages and the discrete choice model of exporting. In fact, in the absence of nominal rigidities, an increase in uncertainty is expansionary and induces more entry into the export market because firms value their ability of adjusting inputs in response to changes in prices and wages. ${ }^{4}$ However, when nominal rigidities impede large price and wage adjustments, this effect is swamped by the increased value of waiting in the face of uncertain future demand so that the intensive margins of entry into and exit from the export market both contribute substantially to the overall drop in economic activity in response to a rise in trade policy uncertainty.

Section 2 presents our measures of trade policy uncertainty. Section 3 describes the empirical effects of trade policy uncertainty. Sections 4 contains the model, and Section 5 shows the model experiments. Section 6 concludes.

\footnotetext{
${ }^{4}$ This is the well known Oi-Hartman-Abel effect that stems from the fact that firms' indirect profit functions are convex in prices and wages. See Alessandria et al. (2015) for a model in which this effect also interacts with firms' entry into and exit from the export market.
} 


\section{$2 \quad$ Measuring Trade Policy Uncertainty}

In this section, we present three measures of trade policy uncertainty (henceforth $T P U$ ). We first describe the construction of our firm-level trade policy uncertainty measure. We then discuss two complementary measures of aggregate $T P U$, one based on newspaper coverage of $T P U$ related news, and the other based on the estimation of a stochastic volatility model for U.S. import tariffs.

\subsection{Firm-Level Trade Policy Uncertainty}

We construct a time-varying, firm-level measure of $T P U$, that we denote by $T P U_{i, t}$, based on text analysis of transcripts of quarterly earnings conference calls of publicly listed companies. Our approach is inspired by the analysis of firm-level political risk in Hassan et al. (2017). ${ }^{5}$ Quarterly earnings conference calls follow a common format: the $\mathrm{CEO}$ or the $\mathrm{CFO}$ of the company opens with an overview of the particular firm's performance in the preceding quarter, and then transitions into a Q\&A session with investors and analysts. The nature of the Q\&A portion of the call is inherently more forward-looking, and it often covers uncertainty and risks faced by the firm. We run text searches of approximately 160,000 transcripts for 7,526 firms, collected from 2005 through the end of 2018 .

Our methodology involves two steps. In the first step, we search each transcript for terms related to trade policy, such as tariff, import duty, import barrier, and (anti-)dumping. ${ }^{6}$ We then construct the indicator $T P_{i, t}$ that measures, for each transcript, the frequency of these words, i.e. the number of mentions divided by the total number of words. The indicator $T P_{i, t}$ proxies for the intensity of trade policy related discussions, irrespective of whether they center on risk and uncertainty. In the second step, we isolate discussions about TPU by further examining the pool of transcripts returning positive values for $T P_{i, t}$. We conduct an initial human audit of these transcripts to devise a list of terms indicating uncertainty, such as risk, threat, uncertainty, worry, concern, volatile, and

\footnotetext{
${ }^{5}$ Hassan et al. (2017) use earnings calls from 2002 through 2016 to study the effects of firm-specific policy uncertainty on current firm-specific investment. One of the political topics is trade uncertainty, which is constructed at the firm level using trade-specific terms in combination with uncertainty terms. There are three important differences between our approach and theirs. First, we focus specifically on TPU. Second, regarding the choice of words, our search places more emphasis on "tariffs" than "trade" since a preliminary audit of earnings calls covering the 20172018 period indicated that "trade" terms such as "all trade" or "trade relations" contained far more false positives than "tariff" words. Third, we emphasize the dynamic effect of trade uncertainty on capital accumulation. Figure A.1 in the Appendix compares our aggregate based on firms' earnings calls with the analogous measure constructed by Hassan et al. (2017). Their measure spikes in 2008Q4, a period of higher economic uncertainty, while our measure does not.

${ }^{6}$ The full list of trade policy terms is: tariff*, import dut*, import barrier*, anti-dumping, trade treat*, trade agreement*, trade polic*, trade act*, trade relationship*, GATT, World Trade Organization/WTO, and free trade. We also search for import*, export*, and border* within three words of either ban*, tax*, or subsid*. An asterisk indicates a search wild card.
} 
tension. $^{7}$ The frequency of joint instances of trade policy and uncertainty terms in each transcript measures the overall uncertainty around trade policy perceived by a firm, $T P U_{i, t} \cdot{ }^{8}$

Figures 1 and 2 highlight the large degree of variation in TPU over time and across industries. We aggregate firm level trade uncertainty by first constructing, for each firm, a dummy variable $\mathcal{I}_{i, t}^{T P U}$ that takes value 1 if the transcript mentions trade policy uncertainty $\left(T P U_{i, t}>0\right)$, and 0 otherwise. Our aggregate measure $T P U_{t}^{f}$ is then given by the proportion of firms that mention $T P U$ in their conference calls, i.e. $T P U_{t}^{f}=\frac{\sum_{i=1}^{\# \text { firms }} \mathcal{I}_{i, t}^{T P U}}{\# \text { firms }}$. Figure 1 shows how companies and media's perceptions of trade uncertainty are remarkably well-aligned: in particular, the aggregated firm-level trade uncertainty measure, $T P U_{t}^{f}$, tracks very closely the aggregate index of trade policy uncertainty constructed from newspaper searches, discussed in the next subsection.

Figure 2 offers additional detail, showing for selected quarters the share of firms with $\mathcal{I}_{i, t}^{T P U}=1$ within an industry. ${ }^{9}$ Our measure has evolved along two dimensions during the sample period. First, the number of firms concerned with trade policy uncertainty has increased over time across nearly all industries. In the first quarter of 2010, less than $2 \%$ of firms discussed trade policy uncertainty in all industries but one. In the last quarter of 2018, about $15 \%$ of the firms' earnings calls contained discussions related to TPU. Second, stronger sectoral variation in TPU is apparent in the data beginning in 2017.

\subsection{Components of Firm-Level Trade Policy Uncertainty}

Readings of the earnings calls offer a window into the different types of concerns expressed by firms mentioning trade policy uncertainty. To this end, we track the words surrounding each mention of trade policy uncertainty to understand why a given company expresses concerns about trade tensions. One firm may fret about the effects of rising input and transportation costs on its bottom line, another might worry about the broader impact on aggregate demand, and another may worry about its supply chain.

We extract from the earnings calls for which $\mathcal{I}_{i, t}^{T P U}=1$ the bigrams within 20 words of the trade uncertainty terms. Next, we summarize the information in the bigrams using Latent Dirichlet Allocation (LDA), an unsupervised machine learning algorithm used to group documents according to the words or phrases that best predict the body of text. Our approach follows, among others,

\footnotetext{
${ }^{7}$ We require the uncertainty-related words to be within ten words of one or more of the initial trade policy-related terms.

${ }^{8} \mathrm{We}$ also conduct a final audit of the $T P U_{i, t}$ measure to minimize instances of false positives. The final $T P U_{i, t}$ is a reliable measure of companies' uncertainty about trade policy, which does not appear to be contaminated by references to trade policy that are unrelated to risk.

${ }^{9}$ We use the Fama-French 12 industry classification. See http://mba.tuck.dartmouth.edu/pages/faculty/ ken.french/Data_Library/det_12_ind_port.html. For any sector $J$, our measure of sectoral $T P U$ is then $S T P U_{j, t}=\frac{\sum_{i \in \text { Sector } J} \mathcal{I}_{i, t}^{T P U}}{\# \text { firms in } J}$.
} 
the work of Hansen, McMahon, and Prat (2017). ${ }^{10}$

Figure 3 provides a visualization of the first four topics covered by the earnings calls, where the size of the words in the cloud is approximately proportional to its probability in the topic, and topics form natural groupings of words recurring together in the same earnings call. Topic 1 mostly refers to the uncertainty surrounding the 2017 proposed border tax adjustment. Topic 2 mentions the potential impact of trade uncertainty on supply chains. Topics 3 and 4 refer to the potential risks associated with higher costs of raw materials as well as to the possibility of price increases stemming from higher expected tariffs.

\subsection{Aggregate Trade Policy Uncertainty}

We complement the firm-level index of $T P U$ with two measures of economy-wide $T P U$ measures constructed using aggregate data.

The first measure is based on searches of newspaper articles that discuss trade policy uncertainty. We run - starting in 1960 - automated text searches of the electronic archives of seven newspapers: Boston Globe, Chicago Tribune, Guardian, Los Angeles Times, New York Times, Wall Street Journal, and Washington Post.

In constructing this aggregate index we closely follow the approach employed for the construction of the firm-level index, except for minor modifications of the search terms to better capture changes in vernacular. For instance, the news-based measure includes mentions of import surcharges, a term commonly used to refer to President Nixon's trade tariffs in the early 1970s. As before, we require that the trade policy terms appear along with uncertainty terms in the same article. ${ }^{11}$ The final aggregate measure represents the monthly share of articles discussing trade policy uncertainty. We index the resulting series to equal 100 for an article share of 1 percent. ${ }^{12}$

The second measure of trade policy uncertainty is estimated using a stochastic volatility model

\footnotetext{
${ }^{10} \mathrm{As}$ is standard practice in textual analysis we pre-process the selected transcripts by removing stop words, such as "the", and by stemming the remaining terms, a technique that reduces the terms to their root. For instance "discussing" becomes simply "discuss". By preprocessing the text in this way we limit the total vocabulary contained in each document to the most essential words.

11 The full set of trade policy words is: foreign competition, protectionism, tariff*, import dut*, import barrier*, trade treat* ${ }^{*}$, trade polic ${ }^{*}$, trade act*, import fee* ${ }^{*}$ tax* (within 10 words of foreign good*, foreign oil, or import* ${ }^{*}$, import* (within 10 words of surtax* or surcharge*), and trade agreement* (Not including NAFTA or North American Free Trade Agreement). We also exclude GATT, WTO, and World Trade Organization. The set of uncertainty words is: concern ${ }^{*}$, fear $^{*}$, pressure $^{*}$, confusion, turmoil, challenge*, uncertain* ${ }^{*}$,isk*, dubious, unclear, dispute*, issue*, potential $^{*}$, probabl $^{*}$, predict $^{*}$, and danger*

12 Baker, Bloom, and Davis (2016) also construct an indicator, available from 1985, of trade policy uncertainty available at http://www.policyuncertainty.com/categorical_epu.html. There are three differences between their index and ours. First, our index adds an additional 25 years of data, extending back to 1960 . Second, the search terms differ slightly, as we never search explicitly for mentions of legislation or institutions such as NAFTA and the WTO. Third, unlike the Baker, Bloom, and Davis (2016) measure, our index is much higher in 2017 and 2018 than during the negotiations that led to signing of North American Free Trade Agreement. Figure A.2 in the Appendix compares our news-based index with Baker et al.'s index.
} 
for import tariff rates. Following Mendoza, Razin, and Tesar (1994) and Fernandez-Villaverde et al. (2015), we construct a quarterly measure of tariff rates, computed as $\tau_{t}=C D_{t} /\left(M_{t}+C D_{t}\right)$, where $C D$ denotes customs duties and $M$ denotes nominal imports of goods. The sample runs from 1960Q1 through 2018Q4. We focus on tariffs because data are readily available and have a natural counterpart in our DSGE models discussed later.

We posit that tariffs $\left(\tau_{t}\right)$ evolve according to:

$$
\begin{aligned}
\tau_{t} & =\left(1-\rho_{\tau}\right) \mu_{\tau}+\rho_{\tau} \tau_{t-1}+\exp \left(\sigma_{t}\right) \varepsilon_{t}, \quad \varepsilon_{t} \sim N(0,1), \\
\sigma_{t} & =\left(1-\rho_{\sigma}\right) \sigma+\rho_{\sigma} \sigma_{t-1}+\eta u_{t}, \quad u_{t} \sim N(0,1)
\end{aligned}
$$

where equation (1) is a fiscal rule for the level of tariffs that follows an autoregressive process with stochastic volatility, and equation (2) models stochastic volatility as an autoregressive process. ${ }^{13}$

Our formulation for the tariff rule incorporates two independent innovations to tariffs. The first innovation $\left(\varepsilon_{t}\right)$ affects the tariff itself and, like a typical fiscal shock, captures taxes on imports not explained by past values of tariffs. The second innovation $\left(u_{t}\right)$ affects the spread of values for tariffs and acts like a volatility shock: A value $\sigma_{t}$ higher than usual, for instance, indicates increased uncertainty about future tariff rates. The parameters of interest are the average log standard deviation of an innovation to fiscal shocks $(\sigma)$, the unconditional standard deviation of the fiscal volatility shock $(\eta)$, and the persistence of the two processes $\left(\rho_{\tau}\right.$ and $\left.\rho_{\sigma}\right)$. We estimate the model using Bayesian techniques. ${ }^{14}$

Columns 2 to 4 in Table 1 report the median and 95 percent credible sets of the posterior distribution of the model parameters. Our estimates indicate that both the tariff rule and the tariff volatility process are very persistent. Innovations to the level of tariffs $\left(\varepsilon_{t}\right)$ have an average standard deviation of $100 \times \exp (-6.14)=0.22$ percentage points. A one-standard deviation innovation to the volatility of tariffs $\left(u_{t}\right)$ increases the standard deviation of innovations to tariff shocks to about $100 \times \exp [-6.14+0.37]=0.31$ percentage points. ${ }^{15}$

\footnotetext{
${ }^{13}$ We also experimented with a level equation that includes feedback from the state of the economy (measured as the cyclical component of output), the level of debt (as a ratio of GDP), and the current account (as a ratio of GDP). Overall, our parameter estimates were not much different but the sample size shrank. Hence, we decided to have the simpler rule as our benchmark specification. The White (1980) and Breusch and Pagan (1979) tests indicate that the null hypothesis of homoskedastic shocks to tariffs is rejected at the $1 \%$ level.

${ }^{14}$ In particular, we use the algorithm of Born and Pfeifer (2014) that employs a particle filter to estimate the unobserved stochastic volatility process. We take 60,000 draws from the posterior distribution of the parameters, discarding the first 10,000 draws.

${ }^{15}$ Fernandez-Villaverde et al. (2015) use a similar approach to estimate uncertainty about capital taxes and find that the average standard deviation of such taxes is 0.75 percentage points. Our estimates are about half as large, consistent with the conventional view that uncertainty about tariff policy over the past decades has been low compared to other fiscal policy instruments.
} 


\section{An Historical Overview of Movements in Aggregate TPU.}

Figure 4 plots the news-based index of $T P U$, while Figure 5 shows the tariff volatility series. For the latter, we plot the median and the 90 percent posterior probability interval. ${ }^{16}$ The resulting series can be interpreted as the percentage point increase in tariffs that would have resulted from a one-standard deviation innovation to the tariff shock at different points in time.

These two figures allow us to build an historical account of uncertainty about trade policy. The news-based TPU and the tariff volatility series share two major spikes in the early 1970s, namely 1971Q4 and 1975Q1-1976Q1. The first spike coincides with what historians often refer to as the "Nixon shock," that is, a unique, unanticipated policy shift in which the U.S. Administration imposed an across-the-board tariff on dutiable imports - the first general tariff increase since the Smoot-Hawley tariff of 1930 (Irwin, 2013). ${ }^{17}$ Notably, this event was relatively short lived and the import tariffs were eventually removed in late December of the same year.

The second spike begins with the January 1975 State of the Union address of President Ford in which he announced measures to address the energy crisis by, among other things, reducing oil imports. The interesting aspect of President Ford's actions is that they were implemented just weeks after Congress had voted on the 1974 Trade Act, which contained a strong push towards opening markets and granting more powers to the President to liberalize trade. Thus, the Ford Administration's use of trade policy instruments to deal with rising oil prices represented a surprising shift in the scope and use of trade policy.

While both TPU measures seem to provide a relatively accurate historical account of U.S. trade policy, they also suffer from a few shortcomings. The tariff volatility measure requires, by construction, changes in tariff rates to signal changes in tariff uncertainty. Hence, it does not capture uncertainty originating from other trade policy actions such as antidumping procedures or (re)negotiations of major trade agreements. ${ }^{18}$ The news-based TPU index seems to better capture additional episodes of trade policy uncertainty that did not coincide with tariff volatility, such as the two spikes at the beginning of Kennedy's presidency — when he proposed a rethinking of America's trade policies - and around the negotiation of the North American Free Trade Agreement in the in the early 1990s. ${ }^{19}$ Absent an empirical model, however, changes in the news-based TPU index are difficult to describe in economic units, as with similar measures of economic policy uncertainty. For this reason, we later calibrate our model experiments using the estimated stochastic volatility process for tariff rates. Notwithstanding these methodological differences, it is reassuring that the two measures describe similar patterns in U.S. history of trade policy, with a contemporaneous correlation of 0.26 .

\footnotetext{
${ }^{16}$ We transform the shocks to express them in the level of tariffs, $\left(100 \times \exp \sigma_{t}\right)$.

${ }^{17}$ The surcharge applied to about half of U.S. imports.

${ }^{18}$ See, for instance, Barattieri, Cacciatore, and Ghironi (2018) for an empirical analysis on the effects of antidumping measures in Canada and Turkey.

${ }^{19}$ See Table A.1 for further discussion of these episodes.
} 


\section{The Effects of Trade Policy Uncertainty}

We now use the measures described in the previous section to get a quantitative sense of the macroeconomic effects of trade policy uncertainty. We proceed in two steps. First, we use firmspecific trade uncertainty to estimate the effects on investment of the recent spike in TPU. Second, we complement these results using historical relationships and by estimating a vector autoregressive (VAR) model of the U.S. economy.

\subsection{Firm-level Responses to Trade Policy Uncertainty}

We start by estimating the dynamic effects of changes in firm-specific $T P U_{i, t}$ on firm-level investment. Disaggregated data allow us to exploit the wide range of variation in actual and perceived trade policy uncertainty across firms and over time. To this end, we combine the firm-level $T P U_{i, t}$ measure with quarterly data from Compustat, which contain balance-sheet variables for the nearuniverse of publicly listed firms. Our strategy is to regress investment at various horizons against contemporaneous values of firm-level $T P U_{i, t}$. This strategy mimics the local projections approach developed by Jorda (2005), with the notable difference that we exploit firm-level variation both in the time-series and in the cross-section of the dependent and independent variables. More precisely, we estimate the following regression:

$$
\log k_{i, t+h}-\log k_{i, t-1}=\alpha_{i}+\alpha_{s, t}+\beta_{h} T P U_{i, t}+\Gamma^{\prime} \mathbf{X}_{i, t}+\varepsilon_{i, t}
$$

where $h \geq 0$ indexes current and future quarters. The goal is to estimate $\beta_{h}$, the dynamic effect on investment of variations in trade uncertainty at the firm level. As described above, trade uncertainty is $T P U_{i, t}$, that is, the number of mentions of trade uncertainty words divided by the total number of words in the firms' earnings calls. Our investment measure is $\log k_{i, t+h}-\log k_{i, t-1}$, where $k_{i, t}$ is the capital stock of firm $i$ at the start of period $t$, following Ottonello and Winberry (2018) and Clementi and Palazzo (2019). $\alpha_{i}$ and $\alpha_{s, t}$ denote firm and sector-by-quarter fixed effects, respectively. $\mathbf{X}_{i, t}$ are firm-level control variables: Tobin's $\mathrm{Q}$, cash flows, openness, one lag of the growth rate of the capital stock, and one lag of the trade policy uncertainty measure. We also control for mentions of trade policy that are not related to uncertainty, i.e. $T P X_{i, t}=T P_{i, t}-T P U_{i, t}{ }^{20}$

\footnotetext{
${ }^{20}$ Our variables are constructed as follows. We measure capital as net property, plant, and equipment (PPENTQ) except in the first period where we initialize the firm's capital stock using the gross level (PPEGTQ). This approach provides a stable estimate of quarterly capital growth over the sample. We measure Tobin's Q as the market value of equity plus the book value of assets minus book value of equity, all divided by the book value of assets (Gulen and Ion, 2015). Cash flows are calculated as cash and short-term investments (CHEQ) scaled by beginning-of-period property, plant, and equipment. Both Tobin's Q and cash flows are winsorized at the 1st and 99th percentiles. Finally, openness is the ratio of exports to usage - where usage is gross output plus imports less exports - at the industry level. Gross output by industry is from the Industry Economic Accounts Data published by the Bureau of Economic Analysis. Exports and imports data are from the U.S. Census Bureau U.S. International Trade and Goods and Services report. These industries account for roughly half of total capital expenditures among Compustat firms.
} 
Our measure of firm-level TPU runs from 2005Q1 through 2018Q4 and covers the near-universe of listed firms. However, we restrict our sample in two dimensions. First, we focus our analysis on the 2015Q1-2018Q4 period. As discussed in Section 2, in the years up to 2015, there has been little movement in aggregate and idiosyncratic TPU: only 1.3 percent of firm-quarter observations mention $T P U$ (i.e., $\mathcal{I}^{T P U}=1$ ) for the years 2005-2018, while mentions jump to 5.1 percent from 2016 through 2018. Second, we include firms in the traded sectors of agriculture, mining, and manufacturing, thus leaving out wholesale and service sectors. Agriculture, mining, and manufacturing account for about one half of the firms in our sample and are the only sectors with data available to construct our openness measure. Between 2015 and 2018, firms in these sectors also mention trade uncertainty more frequently (4.7 vs 1.7 percent) than in remaining sectors. All told, our baseline specification includes a total of 9,835 observations on 1,292 firms. ${ }^{21}$

We estimate equation (3) at horizons $h=0,1,2,3,4$. Figure 6 shows the response of firms' capital after an increase in $T P U$ from 0 to 0.035 , the median value of $T P U$ among firms with positive $T P U$. Accordingly, the figure traces out the differential impact on capital between a firm that is concerned about $T P U$ and another one that is not concerned. Four quarters after the increase in TPU, the capital stock of firms that are worried is 2.5 percent lower.

Table A.2 reports quotes from the transcripts associated with some of the most influential observations in our sample that feature a large negative contribution of trade uncertainty to investment one quarter ahead. While some mentions of trade uncertainty refer to an aggregate component, most of the discussions refer to sector-specific policies, to country-specific policies that affect firms doing business in particular region, or to a combination of the two.

Figure 7 summarizes results for alternative specifications of our econometric framework. Panel 1 shows the response of investment after dropping $\mathbf{X}_{i, t}$ from the baseline specification, while still controlling for lagged investment and lagged TPU. Our results hold irrespective of whether we control for any contemporaneous correlation between TPU and other variables capturing firms' investment opportunities, thus allaying the reverse-causation concern that firms mention TPU as an excuse when business is not doing well.

Panel 2 shows that there is something special about investment and concerns about trade policy, rather than investment and trade policy per se. We replace in equation (3) $T P U_{i, t}$ with $T P_{i, t}$, the frequency of words mentioning trade policy, irrespective of whether uncertainty words are included or not. As the panel shows, unlike for $T P U_{i, t}$, higher $T P_{i, t}$ predicts, if anything, higher investment.

In our baseline specification, the average effect of aggregate trade uncertainty shocks is absorbed by the sector-by-quarter fixed effects $\left(\alpha_{s, t}\right)$. Panel 3 relaxes this restriction by dropping $\alpha_{s, t}$. Under this specification, the effects of an increase in trade policy uncertainty are only slightly attenuated.

\footnotetext{
${ }^{21}$ A detailed description of the variable construction can be found in the Appendix. We further refine our sample by excluding observations for which (i) total assets (ATQ) are less than $\$ 1$ million, (ii) capital expenditures (CAPXY) are negative, and (iii) acquisitions (AQCY) larger than 5 percent percent of assets.
} 


\section{From Firm-level to Aggregate Effects: a back-of-the-envelope calculation}

Are the estimated effects small or large? To boot, our specification does not directly answer the question of how aggregate trade uncertainty affects aggregate investment, since the empirical approach "differences out" any aggregate general equilibrium effect. However, it is possible to make some predictions about aggregate effects by holding fixed any common general equilibrium effects such as endogenous policy responses or spillovers across firms. Between 2017 and 2018, the share of firms in our sample that mentioned trade policy uncertainty in their earnings calls went from 2.8 to 12.9 percent, a 10.1 percentage point increase. Multiplying 10.1 by the 2.53 percent responseafter one year - of capital for a firm that is worried about TPU yields an aggregate decline of capital of 0.26 percent. Since agriculture, mining, and manufacturing account for 43 percent of total assets (ATQ) in 2018, the decline in total capital for all listed firms can be estimated to be $0.101 \times 2.53 \times 0.43=0.11$ percent. Multiplying this number by the net stock of private nonresidential fixed assets, $\$ 24$ trillion, gives a dollar effect of $\$ 26.4$ billion. ${ }^{22}$ This drop amounts to about a 1 percent decline in private nonresidential fixed investment.

\section{Trade Uncertainty, Actual Tariffs, and Industry Investment in 2018}

We conclude the firm-level analysis by zooming in on the industry effects of TPU for the year 2018, the year in our sample witnessing the largest increase in trade policy uncertainty. Our goal is to complement the local projections above with a simple analysis of the differential industry effects of heightened trade tensions in 2018. We construct industry-level changes in capital growth between 2017 and 2018, grouping firms according to the Fama-French 49 industry classifications. By the same token, we construct a variable measuring the change in trade uncertainty at the industry level between 2017 and 2018. The first column of Table 2 reports the results of the cross-sectional regression:

$$
\Delta \log k_{j, 2018}-\Delta \log k_{j, 2017}=\alpha+\beta \Delta S T P U_{j, 2018}+u_{j}
$$

where $\Delta \log k_{j, 2018}$ denotes the log change from 2017 to 2018 in the capital stock for industry $j$, and $\triangle S T P U_{j, 2018}$ measures the standardized change from 2017 to 2018 in trade uncertainty for industry $j{ }^{23}$ The estimated value of $\beta$ is -1.57 . To interpret this number, consider an industry that experienced an increase in TPU that is two times the cross sectional standard deviation of

\footnotetext{
${ }^{22}$ This series is available in line 3 of Table 1.1 of the Fixed Assets Accounts Tables produced by the Bureau of Economic Analysis.

${ }^{23}$ Specifically, we denote by $\log k_{i, 2018}$ the firm's capital stock at the end of 2018 . The change in the capital stock for industry $j$ at the end of year $t$ is constructed as the weighted average of the change in the capital stock of the firms in the industry, $\Delta \log k_{t}=\sum_{i} \omega_{i} \Delta \log k_{i t}$, where $\omega_{i}$ denotes the sectoral capital share of firm $i$ in industry $j$ at $t-1$. Trade uncertainty at the industry level is constructed as the yearly average of the share of industry earnings calls mentioning trade uncertainty. That is, $\triangle S T P U_{j, t}$ is a standardized transformation of

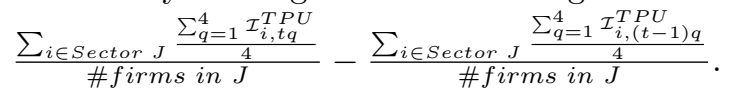


sectoral TPU changes in 2018. This industry is predicted to have reduced its capital growth by about 3.2 percent. Figure 8 offers a visual representation of the strong negative correlation between industry TPU and industry investment in 2018.

In 2018 certain tariffs themselves increased, beckoning the question whether this instance of high TPU simply captures the negative effects of higher tariffs. For each industry, we calculate the share of costs subject to new tariffs in 2018. ${ }^{24}$ Column 2 controls for new tariffs in 2018, reporting the results of the following regression:

$$
\Delta \log k_{j, 2018}-\Delta \log k_{j, 2017}=\alpha+\beta \Delta S T P U_{j, 2018}+\gamma N E W T A R I F F S_{j, 2018}+u_{j}
$$

The coefficient on new tariffs is statistically insignificant. In other words, the industry regression indicates that the impact of tariffs on industry investment has been small, while firms more worried about the escalation of trade tensions have reduced their investment.

\subsection{Macroeconomic Effects of Trade Policy Uncertainty}

There are two important challenges for our firm-level approach. First, how do we interpret firmspecific trade policy uncertainty when there is a large common component? One interpretation is that firm-specific trade uncertainty captures idiosyncratic exposure to a trade policy "shock" that has a strong aggregate component, but whose microeconomic ramifications affect firms and industries differently at different points in time. For instance, two firms in the same industry may buy inputs from suppliers in countries subject to differential trade policy shocks. Another interpretation is that firm-specific uncertainty may capture differential risk aversion and expectations of the managers regarding the same aggregate phenomenon. Under both interpretations, our cross-sectional evidence provides robust support to the notion that trade uncertainty may deter investment, even though the aggregate response is absorbed by the time effects.

Second, how do we convert firm-level responses into aggregate responses when the common component is important? In the previous section, we have provided an estimate of such aggregate effects by implicitly assuming an equivalence between micro and macro effects, and by ruling out any complex general equilibrium effects.

An alternative approach to identify the effects of aggregate trade policy uncertainty relies on the time-honored tradition of estimating a quarterly VAR in the tradition of Christiano, Eichenbaum, and Evans (2005). First, we report evidence based on a bivariate VAR model estimated on the news-based TPU index and real business fixed investment per capita. Then we show that results hold in a model that measures trade uncertainty using tariff volatility shocks and in a larger model that includes a number of macro and financial variables that could help purge the TPU index of

\footnotetext{
${ }^{24}$ We thank Aaron Flaaen at the Federal Reserve Board for constructing and sharing this measure with us. The share is constructed by combining input-output tables with the product list subject to new tariffs published by the U.S. Trade Representative.
} 
movements unrelated to trade policy uncertainty: the tariff rate; real GDP per capita; the Jurado, Ludvigson, and $\mathrm{Ng}$ (2015) macroeconomic uncertainty index; the broad dollar index, and the tax rate on capital income. ${ }^{25}$ We estimate the VAR over the sample 1960-2018. In all specifications, we apply a recursive identification scheme where we order TPU measures first, reflecting our view that our series of tariff volatility are exogenous to the macroeconomy.

Figure 9 plots the responses of trade uncertainty and investment to a two-standard-deviation shock to trade uncertainty under the three VAR model specifications. The solid lines depict the median responses, while the shaded bands represent the corresponding 70 percent point-wise credible sets. The three models provide remarkably consistent results. In response to a $T P U$ shock, trade uncertainty rises on impact and remains elevated for about three years. This prolonged period of uncertainty reduces investment: depending on the model, private investment declines between 1 and 2 percent for about a year. ${ }^{26}$

\section{Validation of Tariff Volatility Shocks}

We conduct the VAR analysis on historical data from 1960 through 2018. While we argue that the TPU shocks we identify are exogenous - validating our identification by controlling for some alternative drivers of the business cycle in the VAR, it is possible that our TPU shocks are contaminated by other sources of macroeconomic instability.

To attenuate these concerns, we run two exercises. First, we look at the correlation between TPU shocks and other traditional macroeconomic shocks, which are external to our VAR model. Second, we look at whether these external shocks Granger-cause the TPU shocks.

We look at four sources of macroeconomic fluctuations that could be relevant for our application: oil shocks, monetary policy shocks, technology shocks, and (non-tariff) fiscal shocks. The oil shocks are from Hamilton (2003) and are based on a nonlinear transformation of the nominal price of crude oil. The monetary policy shocks are from Romer and Romer (2004) where we take the quarterly sum of their monthly variable. Technology shocks are the residual from an AR(1) model of the utilization-adjusted total factor productivity (TFP) (Fernald, 2012). Fiscal shocks are: the news shocks about military spending from Ramey (2011); and the capital tax volatility series of Fernandez-Villaverde et al. (2015).

Table 3 reports the pairwise correlations between these external shocks and the TPU shock identified in the bivariate model, as well as results from the Granger causality tests. These results support the lack of systematic contemporaneous and lagged association between the identified TPU

\footnotetext{
${ }^{25}$ All models include two lags of the endogenous variables and a constant. We use the median of the filtered, instead of the smoothed, tariff volatility series estimated using the stochastic volatility model described in the previous section, so that we can condition on information at time $t$. Per capita variables are constructed using the quarterly civilian non-institutional population. We detrend data prior to estimation using a linear trend.

${ }^{26}$ For comparison, these effects are of similar magnitude to those documented by Fernandez-Villaverde et al. (2015) in their analysis of shocks to capital tax volatility.
} 
shocks and other types of macroeconomic shocks. All correlations and Granger tests are not statistically different from zero and small in economic terms, except for some predictability from changes in TFP, which disappears when shocks are extracted from the multivariate model (not shown).

\subsection{Taking Stock from the Empirical Evidence}

We have presented a variety of methods to measure the empirical effects of movements in trade policy uncertainty. Our firm-level approach finds that firm-level variation in trade policy uncertainty, sized to reflect the developments in 2017-18, can account for an overall decline in investment of about 1 percent. Our estimated VAR also predicts a negative effect of trade uncertainty on investment. When the VAR shock is sized to reflect the trade tensions of 2017 and 2018, the predicted drag on investment is a bit larger, between 1 and 2 percent.

\section{The Model}

In this section, we study the transmission of trade policy risk and uncertainty in a two-country model with heterogenous firms. We augment a New-Keynesian open-economy framework à la Gali and Monacelli (2005) and Corsetti, Dedola, and Leduc (2010) to allow for a discrete choice model of entering and exiting the export market as in Alessandria and Choi (2007). Intermediate goods producing firms specialize in the production of a differentiated good that can be exported provided that the firm finds it profitable to incur an up-front sunk cost to enter the export market, and a smaller period-by-period continuation cost to stay in the export market.

The economy consists of a home $(\mathrm{H})$ country and a foreign $(\mathrm{F})$ country that are isomorphic in structure. We denote foreign variables with an asterisk. Agents in each economy include households, retailers, wholesale firms, distributors, capital good producers, producers of intermediate goods, and the government. The next sections describe the optimization problems solved by each type of agent.

\subsection{Households}

Households in the home country choose final good consumption $\left(C_{t}\right)$, differentiated labor supply and wages for their members $\left(l_{j, t}\right.$ and $w_{j, t}$ for $\left.j \in H\right)$, and a portfolio of assets $\left\{B_{t}(s)\right\}_{s \in S}$ to maximize expected lifetime utility

$$
E_{s} \sum_{t \geq s} \beta^{t-s} U\left(C_{t},\left\{l_{j, t}\right\}_{j \in H}\right)
$$

subject to the budget constraint

$$
P_{t}^{C} C_{t}+\sum_{s \in S} B_{t}(s)+\int A C_{j, t}^{w} d j \leq \int l_{j, t} w_{j, t} d j+\sum_{s \in S} B_{t-1}(s) R_{t}^{B}(s)+\Pi_{t}^{H H}+T_{t}
$$


where $A C_{j, t}^{w}$ is the cost for household member $j$ of adjusting its wage, $R_{t}^{B}(s)$ is the return on asset $B_{t-1}(s), \Pi_{t}^{H H}$ are the aggregate profits of the firms in the home country (which are owned by the home consumers), and $T_{t}$ is a lump-sum transfer from the government. ${ }^{27}$ The wage adjustment cost function is increasing in the aggregate level of employment $\left(L_{t}\right)$ and quadratic in the desired wage change:

$$
A C_{j, t}^{w}=\frac{\rho_{w}}{2}\left(\frac{w_{j t}}{w_{j t-1}}-1\right)^{2} L_{t}
$$

In setting its wage, household member $j$ takes as given intermediate good producers' labor demand:

$$
l_{j, t}=\left(\frac{w_{j t}}{W_{t}}\right)^{-\varepsilon_{w}} L_{t}
$$

where $\varepsilon_{w}$ governs the elasticity of substitution across differentiated labor inputs. Optimality requires the following saving condition:

$$
1=\beta E_{t}\left[\Lambda_{t, t+1} R_{t+1}^{B}(s)\right] \text { for } s \in S
$$

where $\beta \Lambda_{t, t+1}=\beta \frac{U_{C, t+1}}{U_{C, t}}$ is the real stochastic discount factor for the household in the home country.

In a symmetric equilibrium, the optimal decision to supply labor implies a wage Phillips curve of the form:

$$
\left(\pi_{t}^{w}-1\right) \pi_{t}^{w}=\frac{\varepsilon_{w}}{\rho_{w}}\left[-\frac{U_{l_{j}, t}}{U_{C, t}}-\frac{\left(\varepsilon_{w}-1\right)}{\varepsilon_{w}} W_{t}\right]+\beta E_{t} \Lambda_{t, t+1}\left(\pi_{t+1}^{w}-1\right) \pi_{t+1}^{w} \frac{L_{t+1}}{L_{t}}
$$

\subsection{Retailers}

Competitive consumption retailers in the home country combine consumption varieties to produce a final consumption good according to the constant-elasticity of substitution (CES) aggregator

$$
C_{t}=\left[\int C_{t}(i)^{\frac{\varepsilon_{R}-1}{\varepsilon_{R}}} d i\right]^{\frac{\varepsilon_{R}}{\varepsilon_{R}-1}}
$$

where $\varepsilon_{R} \geqslant 0$ determines the elasticity of substitution between consumption varieties. Profits for the consumption retailers are given by $\Pi_{C, t}^{R}=P_{t}^{C} C_{t}-\int P_{t}^{C}(i) C_{t}(i) d i$, where $P_{t}^{C}$ is the price index of the final consumption good and $P_{t}^{C}(i)$ is the price of each individual consumption variety $i$. Given the CES structure of the aggregator, the associated demand schedules are characterized by:

$$
C_{t}(i)=\left[\frac{P_{t}^{C}(i)}{P_{t}^{C}}\right]^{-\varepsilon_{R}} C_{t}
$$

\footnotetext{
27 The resource costs $A C_{j, t}^{w}$ can be interpreted as workers' payments to unions which are in charge of wage negotiations. These costs are then rebated lump sum to the households.
} 
The zero profit condition for the consumption retailers gives the final consumption price index:

$$
P_{t}^{C}=\left[\int P_{t}^{C}(i)^{1-\varepsilon_{R}} d i\right]^{\frac{1}{1-\varepsilon_{R}}}
$$

Similarly, competitive investment retailers in the home country combine investment varieties to produce a final investment good according to the CES aggregator

$$
I_{t}=\left[\int I_{t}(i)^{\frac{\varepsilon_{R}-1}{\varepsilon_{R}}} d i\right]^{\frac{\varepsilon_{R}}{\varepsilon_{R}-1}}
$$

where $\varepsilon_{R} \geqslant 0$ determines the elasticity of substitution between consumption varieties. Profits for the investment retailers are $\Pi_{I, t}^{R}=P_{t}^{I} I_{t}-\int P_{t}^{I}(i) I_{t}(i) d i$, where $P_{t}^{I}$ is the price index of the final investment good and $P_{t}^{I}(i)$ is the price of each individual investment variety $i$. Given the CES structure of the aggregator, the associated demand schedules are characterized by

$$
I_{t}(i)=\left[\frac{P_{t}^{I}(i)}{P_{t}^{I}}\right]^{-\varepsilon_{R}} I_{t}
$$

The zero profit condition for the investment retailers gives the final investment price index

$$
P_{t}^{I}=\left[\int P_{t}^{I}(i)^{1-\varepsilon_{R}} d i\right]^{\frac{1}{1-\varepsilon_{R}}}
$$

\subsection{Wholesale Firms}

Each country features a continuum of monopolistically competitive wholesale firms that produce differentiated consumption varieties. Wholesale firms combine bundles of consumption intermediates produced in the home country $\left(D_{H t}^{C}\right)$ and bundles produced and exported by the foreign country $\left(D_{F t}^{C}\right)$ according to the CES technology:

$$
C_{t}(i)=\left[\omega_{C}^{\frac{1}{\theta_{C}}}\left(D_{H t}^{C}\right)^{\frac{\theta_{C}-1}{\theta_{C}}}+\left(1-\omega_{C}\right)^{\frac{1}{\theta_{C}}}\left(D_{F t}^{C}\right)^{\frac{\theta_{C}-1}{\theta_{C}}}\right]^{\frac{\theta_{C}}{\theta_{C}-1}}
$$

where $\theta_{C} \geqslant 0$ determines the elasticity of substitution between domestic and foreign bundles and $\omega_{C}$ governs the relative share of domestically produced consumption bundles.

Wholesale consumption firms profits are

$$
\Pi_{C, t}^{W}(i)=P_{t}^{C}(i) C_{t}(i)-P_{H t} D_{H t}^{C}-P_{F t}\left(1+\tau_{t}^{m}\right) D_{F t}^{C}-A C_{t}^{P C}(i)
$$

where $P_{H t}$ and $P_{F t}$ are, respectively, the price indexes of the domestic and foreign intermediates, $\tau_{t}^{m}$ is the tariff that the home country may impose on imported intermediates, and $A C_{t}^{P C}(i)$ is a 
(quadratic) cost incurred to adjust prices as in Rotemberg (1982). ${ }^{28}$

For any given level of production $C_{t}(i)$, cost minimization yields the demand functions

$$
\begin{gathered}
D_{H t}^{C}(i)=\omega_{C}\left[\frac{P_{H t}}{M C_{t}^{C}(i)}\right]^{-\theta_{C}} C_{t}(i), \\
D_{F t}^{C}(i)=\left(1-\omega_{C}\right)\left[\frac{P_{F t}\left(1+\tau_{t}^{m}\right)}{M C_{t}^{C}(i)}\right]^{-\theta_{C}} C_{t}(i),
\end{gathered}
$$

where $M C_{t}^{C}(i)$ is the marginal cost function faced by wholesale firms:

$$
M C_{t}^{C}=\left[\omega_{C}\left(P_{H t}\right)^{1-\theta_{C}}+\left(1-\omega_{C}\right)\left(P_{F t}\right)^{1-\theta_{C}}\left(1+\tau_{t}^{m}\right)^{1-\theta_{C}}\right]^{\frac{1}{1-\theta_{C}}} .
$$

These expressions imply that higher tariffs in the domestic country raise the relative cost of imported intermediate inputs and hence shift demand away from imported inputs towards domesticallyproduced intermediate inputs, that is:

$$
\frac{D_{H t}^{C}(i)}{D_{F t}^{C}(i)}=\frac{\omega_{C}}{\left(1-\omega_{C}\right)}\left[\frac{P_{H t}}{P_{F t}\left(1+\tau_{t}^{m}\right)}\right]^{-\theta_{C}}
$$

Moreover, since tariffs are imposed on intermediate goods, higher tariffs raise wholesale firms' marginal costs.

The (dynamic) pricing decision of wholesale firms yields, after imposing symmetry across firms, the Phillips curve expression:

$$
\left(\pi_{t}^{c}-1\right) \pi_{t}^{c}=\frac{\varepsilon_{R}}{\rho_{p}}\left[\mu_{t}^{C}-\frac{\varepsilon_{R}-1}{\varepsilon_{R}}\right]+E_{t} \Lambda_{t, t+1}\left(\pi_{t+1}^{c}-1\right) \pi_{t+1}^{c} \frac{C_{t+1}}{C_{t}}
$$

where $\pi_{t}^{c}=\frac{P_{t}^{C}}{P_{t-1}^{C}}$ and $\mu_{t}^{C}=\frac{M C_{t}}{P_{t}^{C}}$.

Similarly, monopolistically competitive wholesale firms combine bundles of investment intermediates produced in the home country $\left(D_{H t}^{I}\right)$ and bundles produced and exported by the foreign country $\left(D_{F t}^{I}\right)$ to produce differentiated investment varieties according to the CES technology

$$
I_{t}(i)=\left[\omega_{I}^{\frac{1}{\theta_{I}}}\left(D_{H t}^{I}\right)^{\frac{\theta_{I}-1}{\theta_{I}}}+\left(1-\omega_{I}\right)^{\frac{1}{\theta_{I}}}\left(D_{F t}^{I}\right)^{\frac{\theta_{I}-1}{\theta_{I}}}\right]^{\frac{\theta_{I}}{\theta_{I}-1}}
$$

where $\theta_{I} \geqslant 0$ determines the elasticity of substitution between domestic and foreign bundles and $\omega_{I}$ governs the relative shares of domestically produced investment bundles.

\footnotetext{
${ }^{28}$ As with the wage adjustment costs, we interpret the costs of adjusting prices incurred by firms as payments to pricing agencies that are rebated back lump sum to the households.
} 
Profits for wholesale investment firms are

$$
\Pi_{I, t}^{W}(i)=P_{t}^{I}(i) I_{t}(i)-P_{H t} D_{H t}^{I}-P_{F t}\left(1+\tau_{t}^{m}\right) D_{F t}^{I}-A C_{t}^{P I}(i)
$$

The optimality conditions associated with the (static) cost minimization decisions and (dynamic) pricing decisions are ${ }^{29}$

$$
\begin{gathered}
D_{H t}^{I}(i)=\omega_{I}\left[\frac{P_{H t}}{M C_{t}^{I}(i)}\right]^{-\theta_{I}} I_{t} \\
D_{F t}^{I}=\left(1-\omega_{I}\right)\left[\frac{P_{F t}\left(1+\tau_{t}^{m}\right)}{M C_{t}^{I}(i)}\right]^{-\theta_{I}} I_{t} \\
M C_{t}^{I}=\left[\omega_{I}\left(P_{H t}\right)^{1-\theta_{I}}+\left(1-\omega_{I}\right)\left(P_{F t}\right)^{1-\theta_{I}}\left(1+\tau_{t}^{m}\right)^{1-\theta_{I}}\right]^{\frac{1}{1-\theta_{I}}}, \\
\left(\pi_{t}^{I}-1\right) \pi_{t}^{I}=\frac{\varepsilon_{R}}{\rho_{p}}\left[\mu_{t}^{I}-\frac{\varepsilon_{R}-1}{\varepsilon_{R}} p_{t}^{I}\right]+E_{t} \Lambda_{t, t+1}\left(\pi_{t+1}^{I}-1\right) \pi_{t+1}^{I} \frac{I_{t+1}}{I_{t}}
\end{gathered}
$$

where $\pi_{t}^{I}=\frac{P_{t}^{I}}{P_{t-1}^{I}}, \mu_{t}^{I}=\frac{M C_{t}^{I}}{P_{t}^{C}}$, and $p_{t}^{I}=\frac{P_{t}^{I}}{P_{t}^{C}}$.

\subsection{Distributors}

Competitive distributors specialize in the production of (CES) bundles of consumption and investment intermediates purchasing intermediate varieties produced both in the home country and in the foreign country

$$
\begin{gathered}
D_{H t}^{C}+D_{H t}^{I}=D_{H t}=\left[\int y_{H t}(j)^{\frac{\varepsilon_{D}-1}{\varepsilon_{D}}} d i\right]^{\frac{\varepsilon_{D}}{\varepsilon_{D}-1}} \\
D_{F t}^{C}+D_{F t}^{I}=D_{F t}=\left(N_{t}^{*}\right)^{-\lambda \frac{\varepsilon_{D}}{\varepsilon_{D}-1}}\left[\int_{j \in E_{t}^{*}} y_{F t}(j)^{\frac{\varepsilon_{D}-1}{\varepsilon_{D}}} d i\right]^{\frac{\varepsilon_{D}}{\varepsilon_{D}-1}}
\end{gathered}
$$

where $\varepsilon_{D} \geqslant 0$ determines the elasticity of substitution between varieties. As in Alessandria and Choi (2007), the aggregator for foreign varieties includes the fraction of foreign intermediates available in the home country $\left(N_{t}^{*}\right)$ to separate between love-of-variety effect embedded in the aggregator from the pure degree of market power $\left(\varepsilon_{D}\right)$. The set $E_{t}^{*}$ includes foreign exporting firms.

Profits of distributors are

$$
\Pi_{H t}^{D}=P_{H t} D_{H t}-\int P_{H t}(j) y_{H t}(i) d i
$$

\footnotetext{
29 The implicit assumption is that countries set a uniform tariff rate on both consumption and investment imported intermediates.
} 


$$
\Pi_{F t}^{D}=P_{F t} D_{F t}-\int P_{F t}(j) y_{F t}(i) d i
$$

The optimality conditions associated with profit maximization yield the demand schedules

$$
\begin{gathered}
y_{H t}(i)=\left[\frac{P_{H t}(j)}{P_{H t}}\right]^{-\varepsilon_{D}} D_{H t}, \\
y_{F t}(i)=\left(N_{t}^{*}\right)^{-\lambda \varepsilon_{D}}\left[\frac{P_{F t}^{C}(j)}{P_{F t}^{C}}\right]^{-\varepsilon_{D}} D_{F t} .
\end{gathered}
$$

Finally, the associated price indexes are

$$
\begin{gathered}
P_{H t}=\left[\int_{j \in E_{t}^{*}} P_{H t}(j)^{1-\varepsilon_{D}} d i\right]^{\frac{1}{1-\varepsilon_{D}}}, \\
P_{F t}=\left(N_{t}^{*}\right)^{-\lambda \frac{\varepsilon_{D}}{\varepsilon_{D}-1}}\left[\int_{j \in E_{t}^{*}} P_{F t}(j)^{1-\varepsilon_{D}} d i\right]^{\frac{1}{1-\varepsilon_{D}}} .
\end{gathered}
$$

\subsection{Capital Goods Producers}

The supply of aggregate capital is determined by the problem of competitive capital good producers facing investment adjustment costs as in Christiano, Eichenbaum, and Evans (2005). We incorporate investment adjustment costs since this specification bears predictions for investment dynamics that closely match the data both at the macro and at the micro level (see for instance Eberly, Rebelo, and Vincent, 2012). Let the increase in the aggregate capital stock be given by

$$
I_{t}^{k}=K_{t}-(1-\delta) K_{t-1}
$$

Capital good producers use consumption goods and investment goods in order to produce final capital goods $I_{t}^{k}$. In particular they use one unit of investment goods $I_{t}$ for each unit of $I_{t}^{k}$ and they also face quadratic adjustment cost whenever they change the overall amount of $I_{t}^{k}$, given by $\frac{\kappa}{2}\left(\frac{I_{t}^{k}}{I_{t-1}^{k}}-1\right)^{2}$. Their problem is then to choose $I_{t}^{k}$ to solve:

$$
\max E_{s} \sum_{t \geq s} \beta^{t-s} \Lambda_{t, s}\left(p_{t}^{k} I_{t}^{k}-I_{t}^{k}\left[p_{t}^{I}+\frac{\kappa}{2}\left(\frac{I_{t}^{k}}{I_{t-1}^{k}}-1\right)^{2}\right]\right)
$$

Their optimality condition is:

$$
p_{t}^{k}=p_{t}^{I}+\frac{\kappa}{2}\left(\frac{I_{t}^{k}}{I_{t-1}^{k}}-1\right)^{2}+\kappa\left(\frac{I_{t}^{k}}{I_{t-1}^{k}}-1\right) \frac{I_{t}^{k}}{I_{t-1}^{k}}-E_{t} \beta \Lambda_{t, t+1} \kappa\left(\frac{I_{t+1}^{k}}{I_{t}^{k}}-1\right)\left(\frac{I_{t+1}^{k}}{I_{t}^{k}}\right)^{2} .
$$




\subsection{Producers of Intermediate Varieties}

Our model of intermediate varieties producers follows Alessandria and Choi (2007). In each country, a unit mass of monopolistically competitive firms is indexed by $j \in[0,1]$. Each firm produces output for the domestic market $\left(y_{H t}\right)$ and, if it decides to export, for the foreign market $\left(y_{H t}^{*}\right)$, according to a constant returns to scale technology:

$$
y_{H t}(j)+m_{t}(j) y_{H t}^{*}(j) \leq A_{t} z_{t}(j) k_{t}(j)^{\alpha} l_{t}(j)^{1-\alpha},
$$

where $m_{t}(j) \in\{0,1\}$ is an indicator function denoting whether or not firm $j$ decides to export in the current period, $A_{t}$ is an autoregressive aggregate productivity shock, $z(j)$ is an idiosyncratic i.i.d. productivity shock, $k_{t}(j)$ is the producer's capital stock, and $l_{t}(j)$ is the amount of labor used in production.

Within-period profits are

$$
\Pi_{t}^{P}(j)=P_{H t}(j) y_{H t}(j)+m_{t}(j) \varepsilon_{t} P_{H t}^{*}(j) y_{H t}^{*}(j)-W_{t} l_{t}(j)-P_{t}^{I} i_{t}(j)
$$

where $\varepsilon_{t}$ is the nominal exchange rate, $P_{H t}^{*}$ is the price charged in the export market (in foreign currency), and $W_{t}$ is the aggregate wage.

When a firm decides to export $\left(m_{t}=1\right)$, it incurs a fixed cost $f\left(m_{t-1}\right)$ in units of labor that depends on its export status in the previous period. Specifically, firms pay a sunk cost to enter the export market, denoted by $f(0)$, that is higher than the fixed cost of continuing exporting in each period $f(1)$. If a firm exits the export market, it must repay the sunk cost $f(0)$ to reenter. ${ }^{30}$

Firms accumulate capital according to the law of motion

$$
k_{t+1}(j) \leq(1-\delta) k_{t}(j)+i_{t}(j)
$$

where $\delta$ is the depreciation rate.

Each intermediate good producer solves the following dynamic recursive problem

$$
V\left(z_{t}, m_{t-1}, k_{t} ; S_{t}\right)=\max _{m_{t}, i_{t}, k_{t+1}, l_{t}, P_{H t}, P_{H t}^{*}} \Pi_{t}^{P}-W_{t} m_{t} f\left(m_{t-1}\right)+E_{t} \Lambda_{t, t+1} V\left(z_{t+1}, m_{t}, k_{t+1} ; S_{t+1}\right)
$$

given the production technology (40), the law of motion for capital (42), and the demand schedules in the domestic and foreign markets

$$
y_{H t}(i)=\left[\frac{P_{H t}(j)}{P_{H t}}\right]^{-\varepsilon_{D}} D_{H t}
$$

\footnotetext{
${ }^{30}$ In the Alessandria and Choi (2007) formulation, the fixed costs are per variety cost of starting exporting. This assumption rules out economies of scale to exporting, that is, the possibility that a single firm pays the sunk cost and exports multiple varieties of intermediate goods.
} 


$$
y_{H t}^{*}(i)=N_{t}^{-\lambda \varepsilon_{D}}\left[\frac{P_{H t}^{*}(j)}{P_{H t}^{*}}\right]^{-\varepsilon_{D}} D_{H t}^{*} .
$$

The triple $\left(z_{t}, m_{t-1}, k_{t}\right)$ represents the individual state of the firm while the variable $S_{t}$ summarizes the aggregate state.

The optimal price setting requires charging a constant markup over marginal costs

$$
p_{H t}(j)=Q_{t} p_{H t}^{*}(j)=\frac{\varepsilon_{D}}{\varepsilon_{D}-1} \frac{W_{t} l_{t}}{(1-\alpha)\left[y_{H t}+m_{t} y_{H t}^{*}\right]}
$$

The labor demand function, after taking into account these pricing rules and the demand functions for intermediate goods in (44) and (45), can be expressed as

$$
l=\left(k_{t}\right)^{1-v} z^{\left(\varepsilon_{D}-1\right) v}\left(\frac{W_{t}}{\xi}\right)^{-\varepsilon_{D} v} \Gamma_{t}\left(m_{t}\right)^{v}
$$

where the term $\Gamma_{t}\left(m_{t}\right)$ captures how the size of the market that firms serve depends on its export decision $m_{t}$ :

$$
\Gamma_{t}\left(m_{t}\right)=p_{H, t}^{-\varepsilon_{D}}\left(D_{H t}+m_{t} N_{t}^{-\lambda \varepsilon_{D}} D_{H t}^{*}\right) .
$$

Above, the parameters $v$ and $\xi$ depend on the labor share and the elasticity of substitution across intermediate goods as follows:

$$
\begin{aligned}
& v=\frac{1}{1+\alpha\left(\varepsilon_{D}-1\right)} \\
& \xi=(1-\alpha) \frac{\varepsilon_{D}-1}{\varepsilon_{D}} .
\end{aligned}
$$

Under our maintained assumption that intermediate goods are substitutes, i.e. $\varepsilon_{D}>1$, both $v$ and $\xi$ are between 0 and 1 .

The optimality condition for investment is

$$
p_{t}^{k}=E_{t} \Lambda_{t, t+1} V_{k, t+1}(j)
$$

Since the idiosyncratic technology shocks $z_{t}$ are i.i.d. across firms, equation (51) implies that $k_{t+1}$ depends on the firm's export status in the following period $\left(m_{t}\right)$, but is indepedent of $z_{t}$. Consequently, the distribution of capital across firms degenerates to two mass points

$$
k_{t+1}= \begin{cases}K_{t+1}^{0} & \text { if } m_{t}=0 \\ K_{t+1}^{1} & \text { if } m_{t}=1\end{cases}
$$

The decision to enter the export market can be summarized by the productivity threshold $z_{m t}$ that equates the maximal values of exporting and not exporting for a firm entering time $t$ with export 
status $m_{t-1}=m$ :

$$
V^{1}\left(z_{m t}, m, K_{m t} ; S_{t}\right)=V^{0}\left(z_{m t}, m, K_{m t} ; S_{t}\right)
$$

Using the pricing rule and the labor demand in equations (46) and (47), we can write (53) as:

$$
\begin{aligned}
p_{t}^{k}\left(K_{t+1}^{1}-K_{t+1}^{0}\right)+W_{t} f(m)= & {\left[z_{m t}^{\left(\varepsilon_{D}-1\right) v}(1-\xi)\left(\frac{W_{t}}{\xi}\right)^{1-\varepsilon_{D} v}\left(K_{m t}\right)^{1-v}\right]\left[\Gamma_{t}(1)^{v}-\Gamma_{t}(0)^{v}\right](54) } \\
& +E_{t} \Lambda_{t, t+1}\left[V\left(z^{\prime}, 1, K_{t+1}^{1} ; S_{t+1}\right)-V\left(z^{\prime}, 0, K_{t+1}^{0} ; S_{t+1}\right)\right]
\end{aligned}
$$

The left-hand side of (54) represents the extra costs faced by firms to export, that is, a larger capital investment required to serve a larger market, $\left(K_{t+1}^{1}>K_{t+1}^{0}\right)$, and the fixed cost to either enter $\left(m_{t-1}=0\right)$ or stay $\left(m_{t-1}=1\right)$ in the export market. The right-hand side represents the benefits of exporting, that is, the gains from serving a larger makert immediately, captured by the term $\left[\Gamma_{t}(1)^{v}-\Gamma_{t}(0)^{v}\right]$, and the expected larger continuation value of entering in the following period as an exporter. The continuation value includes the benefit for exporters of only paying the continuation costs $f(1)<f(0)$ to continue to export.

Finally, the fraction of exporters $\left(N_{t}\right)$ evolves according to the law of motion

$$
N_{t}=\left[1-\Phi\left(z_{1 t}\right)\right] N_{t-1}+\left[1-\Phi\left(z_{0 t}\right)\right]\left(1-N_{t-1}\right)
$$

\subsection{Government Policy and Equilibrium}

To close the model we specify a rule for monetary and fiscal policies. The monetary authority follows a standard Taylor rule

$$
R_{t}=\frac{1}{\beta}\left[\beta R_{t-1}\right]^{\rho_{R}}\left[\left(\pi_{t}\right)^{\phi_{\pi}}\left(\widetilde{y}_{t}\right)^{\phi_{y}}\right]^{1-\rho_{R}}
$$

where $\rho_{R}$ governs the intertia in the policy rule, $\phi_{\pi}$ is the weight on consumer price inflation $\left(\pi_{t}\right)$, and $\phi_{y}$ is the weight on the output gap $\left(\widetilde{y}_{t}\right)$.

The government balances its budget period by period

$$
\frac{\tau_{t}^{m}}{1+\tau_{t}^{m}} P_{F t} D_{F t}^{C}=T_{t}
$$

where tariffs $\tau_{t}^{m}$ are assumed to follow a first-order autoregressive process with stochastic volatility

$$
\begin{gathered}
\tau_{t}^{m}=\left(1-\rho_{\tau}\right) \mu_{\tau}+\rho_{\tau} \tau_{t-1}^{m}+\exp \left(\sigma_{t-1}^{m}\right) \varepsilon_{t}^{\tau}+\varepsilon_{t-1}^{N} \\
\sigma_{t}^{m}=\left(1-\rho_{\sigma^{m}}\right) \sigma^{m}+\rho_{\sigma^{m}} \sigma_{t-1}^{m}+\eta u_{t}
\end{gathered}
$$


Finally, aggregate productivity follows a first-order vector autoregressive process

$$
Z_{t}=M Z_{t-1}+\varepsilon_{t}^{Z}
$$

where $M$ is a matrix of coefficients, $Z=\left[A_{t}, A_{t}^{*}\right]^{\prime}$, and $\varepsilon_{t}^{Z}=\left[\varepsilon_{t}^{A}, \varepsilon_{t}^{A^{*}}\right]^{\prime \text { i.i.d. }} \sim(0, \Sigma)$. As mentioned earlier, the idiosyncratic productivity shock is such that $z_{t}(j) \stackrel{\text { i.i.d. }}{\sim} N\left(0, \sigma_{z}^{2}\right)$.

The definition of equilibrium is standard. ${ }^{31}$

\section{$5 \quad$ Model Results}

Given our interest in quantifying the macroeconomic effects on trade policy risk and uncertainty, we solve the model using a third-order perturbation method. As discussed in Fernandez-Villaverde et al. (2015), innovations to volatility shocks have direct effects only through third-order terms.

\subsection{Calibration}

In our experiments, we assume that asset markets are incomplete and only noncontingent bonds are traded. We calibrate the model using standard values from the literature as well as drawing from the VAR evidence described above to discipline the stochastic process for tariffs. The calibration is described in Table (4).

We assume a GHH utility function that features habit in consumption:

$$
U(C, L)=\frac{\left[\left(C_{t}-b C_{t-1}\right)-\psi L_{t}^{\mu}\right]^{1-\gamma_{R}}}{1-\gamma_{R}}
$$

where the habit formation parameter $b$ is set equal to 0.75 , the Frisch elasticity parameter $\mu$ is 1 , and the risk aversion parameter $\gamma_{R}$ is 2 . We assume a discount factor $\beta$ of 0.99 . The use of GHH preferences is well established in open-economy models (see, for instance, Mendoza (1991) and Raffo (2008)) as well as in analysis of news shocks (see, for instance, Jaimovich and Rebelo (2009)). We include habit in consumption simply to obtain hump-shaped responses in consumption, thus reducing the impact response of consumption to tariffs and tariff uncertainty shocks. We explore the role of our preference specification in the robustness section, when we compare our baseline results with those from an alternative specification that uses preferences of the form $\frac{C_{t}^{1-\gamma_{R}}}{1-\gamma_{R}}-\psi L_{t}^{\mu}$.

Turning to the calibration of the nominal rigidities, we set the wage and price stickiness parameters $\left(\rho_{w}, \rho_{p}\right)$ to a value that would replicate, in a linearized setup, the slope of the wage and price Phillips curve derived using Calvo stickiness with an average duration of wages and prices

\footnotetext{
${ }^{31}$ For details, see derivations in the Appendix.
} 
of 8 quarters. ${ }^{32}$ The elasticity of labor and good demands associated with these monopolistically competitive pricing decisions $\left(\varepsilon_{w}, \varepsilon_{R}\right)$ is equal to 10 .

In our baseline, we set the Armington elasticity of both consumption and investment goods $\left(\theta_{C}, \theta_{I}\right)$ to 1.5 , as in e.g. Backus, Kehoe, and Kydland (1994). We assume that the home bias in the production of both consumption and investment goods $\left(\omega_{c}\right)$ is 0.85 . We set the capital share of traded goods $(\alpha)$ to 0.36 , and the depreciation rate $(\delta)$ to 0.025 . We set the parameter governing investment adjustment costs $(\kappa)$ to 10 . Conditional on aggregate TFP shocks only, such a value allows the model to reproduce a standard deviation of investment that is about 3 times larger than that of GDP, consistent with data.

The calibrated parameters for the production of intermediate goods follow closely Alessandria and Choi (2007). We set the elasticity of intermediate goods demand $\varepsilon_{D}$ to 5 , while the fixed costs $f(0)$ and $f(1)$ and the dispersion of idiosyncratic productivity $\left(\sigma_{z}\right)$ are set to target quarterly starter and stopper ratios of $n_{1}=n_{0}=3.5$ percent and an exporter premium of 12 percent. We assume that the love-of-variety is tied to the elasticity of substitution across varieties and set $\lambda=0$.

In the Taylor rule $(56)$, the inertia coefficient $\left(\rho_{R}\right)$ is 0.85 , the coefficient on inflation $\left(\phi_{\pi}\right)$ is 1.5 , and the coefficient on the output gap $\left(\phi_{y}\right)$ is set to 0 .

Turning to the calibration of the exogenous processes in Table 4, we set the parameters describing the process for the tariff rate to the median estimates reported in Table 1. The parameters governing the remaining exogenous processes are taken from Alessandria and Choi (2007).

\subsection{Model Experiments}

We use our model to describe how a rise in trade tensions is transmitted to the macroeconomy. Given the estimated autoregressive process with stochastic volatility for import tariffs, in our baseline experiment we model a rise in trade tensions as both a first moment shock (i.e. an increase in the expectation of future tariffs) and a second moment shock (i.e. an increase in the uncertainty about future tariffs). ${ }^{33}$ Throughout our quantitative analysis we retain the assumption of full retaliation by the foreign country.

As in the empirical section, our baseline model experiment is largely calibrated following the trade policy developments of 2018. We size the initial increase in both the expected level of future tariffs, i.e. shock $\varepsilon_{1}^{N}$ in (58), and the uncertainty of future tariffs, i.e. shock $u_{1}$ in (59), by using the threatened level of tariff rates on U.S. imports. Specifically, we assume that in the first period agents learn that trade negotiations between the two countries have begun. Agents forecast that, with equal

\footnotetext{
${ }^{32}$ Our value for price rigidity is in line with recent estimates of the slope of the Phillips curve as in Del Negro, Giannoni, and Schorfheide (2015). We later discuss the importance of price rigidity for the transmission of tariff uncertainty shocks and compare with the flexible price economy.

${ }^{33}$ We thank our discussant Joseph Steinberg for suggesting to combine both shocks in a single experiment. Bloom et al. (2018) follow a similar approach and provide evidence that recessions are best described as unexpected changes in productivity with negative first moments and positive second moments.
} 
probability, tariffs will either remain at their steady-state level $\tau^{S S}=0.02$, the current average tariff rate on U.S. imports, or rise to a higher value $\tau^{H I G H}=0.08$, the threatened level of tariff rate on U.S. imports. ${ }^{34}$ As a consequence of the news about future trade negotiations, agents expect that tariffs will rise by 3 percentage points, $\varepsilon_{1}^{N}=E_{t} \Delta \tau_{t+1}^{m}=0.5(0.08-0.02)$, and the standard deviation of future tariff changes also rises to 3 percentage points, $\exp \left(u_{1}\right) \bar{\sigma}=\sigma\left(\Delta \tau_{t+1}^{m}\right)=0.03$. Thereafter, tariff volatility $\sigma_{t}$ reverts back to its long-run value according to the stochastic process described in (59). We also assume that as agents observe no rise in tariffs they revise their beliefs that tariffs will increase in the subsequent period in a way that is consistent with the path for the volatility process $\sigma_{t}$. That is, $\varepsilon_{t}^{N}=p\left(\sigma_{t}\right)(0.08-0.02)$, where $p\left(\sigma_{t}\right)$ is the probability of observing a rise in tariffs by 6 percentage points in the subsequent period that implies an uncertainty about tariff rates in the subesequent period consistent with $\sigma_{t}$.

Figure 10 presents the response of the economy to this rise in trade tensions in our baseline experiment together with the effects in isolation of news of possible future higher tariffs and of higher tariff volatility. ${ }^{35}$ A rise in trade tensions leads to a sizable decline in consumption, investment, GDP, and consumer price inflation. Real marginal costs of retailers decline, indicating that these firms increase markups in response to trade tensions. ${ }^{36}$ The expectation of a smaller export market leads to a reduction in the fraction of exporters and a lower accumulation of capital by these firms compared to non-exporters. Monetary policy responds to these developments by cutting interest rates. This contraction in aggregate demand and trade happens in the absence of any increase in current tariffs, with news of higher future tariffs explaining about two-thirds of the declines in macroeconomic aggregates.

Quantitatively, our baseline findings are broadly in line with the empirical evidence discussed in Section 2. The decline in aggregate investment, which accounts for a significant portion of the contraction in GDP, falls within the range of responses estimated in our VAR section. And to the extent that the exporting firms in the model are representative of the Compustat firms that experienced sizable increases in their TPU, a rise in trade tensions would reduce exporters' capital accumulation to a greater extent than nonexporters', consistent with our regression results. ${ }^{37}$ Additionally, the model responses also show a sizeable decline in the fraction of exporting firms, consistent with a larger hit to the exporting sectors that are exposed to higher trade uncertainty.

\footnotetext{
${ }^{34}$ Steinberg (2019) uses a dynamic trade model to assess the macroeconomic impact of uncertainty about Brexit on the U.K. economy.

${ }^{35}$ Although the third-order approximation used to solve the model involves non-linear interaction effects of different shocks, in our simulations these additional terms turn out to be quantitively small. Hence, the baseline experiment is roughly approximated by the sum of the responses to the tariff news and increased volatility shocks.

${ }^{36}$ Given our assumption of Rotemberg pricing, the gross markup equals the inverse of the marginal costs.

${ }^{37}$ While our estimates in the empirical section point to growing differences in investment over time, however, the response of relative investment in the model tends to turn positive fairly quickly. Our guess is firm-specific capital adjustment costs, which we ignore in the model setup, are likely to be an empirically important determinant of firm-level investment, thus accounting for the diverging time profile in the two responses. We leave this investigation to future research as it does pose significant aggregation challenges in terms of model solution.
} 
We next turn to the discussion in isolation of the transmission of news about higher expected tariffs and of increased uncertainty about future tariffs.

\subsection{Anticipation Effects of Tariff Shocks}

A large literature studies the transmission of trade policies in macroeconomic models. ${ }^{38}$ It is generally well known that tariffs shift demand from imports to domestically produced goods and act as a tax on labor and capital because they increase domestic consumption and investment prices. Temporary trade policy changes have additional macroeconomic consequences via intertemporal substitution effects. Here we make use of some of these mechanisms to study the effects of news about tariff shocks.

Figure 11 presents the effects of news about higher expected tariffs in both countries together with a sensitivity analysis to key parameters affecting transmission. Starting with the baseline experiment, higher expected tariffs involve an intertemporal substitution channel and an aggregate supply channel that work in opposite directions. Given that consumption and investment prices are expected to be higher in the future, the intertemporal substitution channel pushes current consumption and investment up. However, higher future tariffs also increase the expected cost of importing. Wholesale firms respond by increasing markups, which reduces labor supply and consumption. In addition, higher future tariffs also reduce the expected benefit of exporting by shrinking the expected size of the export markets (i.e. in the expression (54) the term $\left[\Gamma_{t}(1)^{v}-\Gamma_{t}(0)^{v}\right]$ falls). Given rigid wages, the fraction of exporters falls significantly. On balance, the strength of the aggregate supply channel dominates and the economy experiences a persistent decline in GDP.

The transmission of higher expected tariffs is qualitatively robust to a number of parameter variations. Starting from the economy with flexible prices and wages, news about higher expected tariffs reduces GDP, investment, and the fraction of exporters, and leaves consumption essentially unchanged. The decline in investment is about half as large as the decline observed in the baseline economy, indicating that nominal rigidities play an important role in the amplification of expected tariff shocks. As noted before, when prices and wages are rigid, wholesale firms increase domestic markups which acts as a tax on labor supply and consumption. Under flexible prices, markups are constant and this wedge in the labor supply condition is eliminated, inducing a smaller decline in labor supply and consumption. In addition, fewer intermediate good firms are forced to exit the export market - as wages adjust freely — and investment falls by less.

We next investigate the role of firm heterogeneity and of GHH preferences. When we shut down the Alessandria and Choi (2007) bloc of the model - by setting the sunk and continuation costs of exporting equal to zero - the baseline economy reduces to a standard macroeconomic model with Armington trade. Overall, the response of the main macroeconomic variables of interest is some-

\footnotetext{
${ }^{38}$ For recent contributions, see for instance Barattieri, Cacciatore, and Ghironi (2018), Chari (2018), and Erceg, Prestipino, and Raffo (2018)
} 
what smaller than in the baseline economy, but transmission is not greatly affected. ${ }^{39}$ Similarly, with separable preferences, wealth effects on labor supply attenuate the decline of investment, consumption, and output, but do not affect transmission qualitatively. ${ }^{40}$ In particular, with separable preferences news about higher future tariffs increase labor supply through negative wealth effects, thus in part offsetting the labor wedge distortion originating from higher domestic markups.

\subsection{Uncertainty Effects of Tariff Shocks}

Figure 12 presents the effects of an increase in uncertainty about future tariffs in both countries together with a sensitivity analysis to key parameters affecting transmission. Higher uncertainty about future tariffs reduces investment, consumption, and GDP through two main channels. First, wholesale firms increase markups because of an upward bias pricing, as in Fernandez-Villaverde et al. (2015). Second, intermediate good firms find it less profitable to export. We next describe each channel in greater detail.

Price rigidities and markups are central to the transmission of tariff uncertainty shocks. With Rotemberg price adjustment costs, the firm's marginal profit function is convex (i.e. the profit function is asymmetric in the optimal price), as the firm has to satisfy demand at a given price. In other words, the firm's cost of charging a lower price than its competitors is much larger than the cost of charging a higher price. Since higher uncertainty about future tariffs increases the variance of future desired prices, wholesale firms self-insure by increasing markups to avoid having a relatively low price in the future. Higher markups reduce labor supply and consumption. The simulations under flexible prices (red dashed lines) confirm the key role of price rigidities in accounting for the effects of unexpected changes in tariff volatility. Absent price rigidities, investment, consumption, and GDP actually expand via standard Oi-Hartman-Abel effects. ${ }^{41}$

As discussed in Fernandez-Villaverde et al. (2015), the strength of this mechanism critically depends on the elasticity of substitution across goods $\left(\varepsilon_{R}\right) \cdot{ }^{42}$ To gauge the quantitative importance of this parameter, the dashed orange lines present simulations obtained by increasing $\varepsilon_{R}$ from 10 to 21, the benchmark value used in Fernandez-Villaverde et al. (2015), while adjusting the Rotemberg pricing cost to keep the same level of price rigidity as in the baseline experiment. Higher substitutability across goods reduces the monopoly power of firms and gives even stronger

\footnotetext{
39 This finding is broadly in line with the original Alessandria and Choi (2007) paper.

${ }^{40}$ In this experiment we also eliminate habit in consumption to facilitate comparison with preferences typically used in the literature. The addition of consumption habit simply generates hump-shaped responses in consumption and GDP but does not affect transmission and magnitudes.

41 See also Bloom (2009), Basu and Bundick (2012), and Alessandria et al. (2015)

42 The strength of this mechanism also relies on a positive unconditional correlation between firms' demand and marginal costs. Our simulations suggest that uncertainty about future tariffs causes a decline in both marginal costs and consumption. This result may appear surprising because tariffs increase the price of intermediate inputs and, thus, increase marginal costs. While that is the case, the increase in marginal costs is extremely short-lived and firms anticipate that marginal costs and demand eventually decline together, thus sharing positive comovement.
} 
incentives to charge higher prices in response to higher uncertainty about tariffs. The associated declines in investment, consumption, and GDP are larger than in the baseline experiment.

Turning to the export decisions, higher uncertainty about future tariffs also reduces the incentive to export through market size effects. Recall from (54) that the relative size of the domestic and foreign markets is a key determinant of the willingness of firms to pay the fixed cost of exporting. An increase in tariff uncertainty reduces the expected value of having access to a larger market, thus decreasing the fraction of exporters and investment. As in the case of tariff news, we find that eliminating the fixed cost of exporting (i.e. eliminating the endogenous export decision) reduces somewhat the response of the main macroeconomic variables of interest (see dashed blue lines). Hence, we conclude that the endogenous export decision provides an amplification mechanism, but does not greatly affect the transmission of uncertainty shocks. The strength of this effect, however, critically depends on the degree of market power of intermediate good firms. As shown by the green line, when we increase the elasticity of substitution across varieties $\left(\varepsilon_{D}\right)$ from 5 to 11 (which implies a decline in markups from 25 percent to 10 percent), the observed reduction in investment, GDP, and consumption in response to second moment shocks is lower. For the marginal exporter, equation (54) implies that an increase in uncertainty involves a horserace between two opposing forces. On the one hand, higher uncertainty about demand deters firms from paying the fixed cost of exporting as the expected gain of serving a larger market, $E_{t}\left[\Gamma_{t+1}(1)^{v}-\Gamma_{t+1}(0)^{v}\right]$, declines. On the other hand, higher uncertainty about demand provides more incentives to expand production

through the term $\left[z_{m t}^{\left(\varepsilon_{D}-1\right) v}(1-\xi)\left(\frac{W_{t}}{\xi}\right)^{1-\varepsilon_{D} v}\left(K_{m t}\right)^{1-v}\right]$, which captures Oi-Hartman-Abel effects. Reduced market power (i.e. a higher $\varepsilon_{D}$ ) makes the latter effects stronger.

Our last robustness exercise illustrates the importance of $\mathrm{GHH}$ preferences for the transmission of uncertainty shocks. When we adopt separable preferences, uncertainty shocks have negligible effects on macroeconomic variables. This result indicates that negative wealth effects are an important offsetting force that expands labor supply and supports consumption in response of uncertainty shocks, an intuition laid out in Bloom (2009) in the context of second moment productivity shocks. Indeed, these authors conjectured that with $\mathrm{GHH}$ preferences consumption would probably decline in their environment after an increase in uncertainty about productivity. Our findings suggest that GHH preferences are likely to be a key ingredient of general equilibrium models set up to reproduce declines in macroeconomic variables in response to changes in uncertainty, while preserving comovement among them.

\section{Conclusion}

The renegotiation of major trade arrangements in Europe and North America as well as the increasing number of trade disputes across countries suggest that the prospects for global trade integration are far from certain. In this paper, we provided a first attempt at quantifying the macroeconomic 
effects of changes in trade policy uncertainty both empirically and theoretically. We presented three TPU measures constructed for the United States from textual analysis of firm's earning calls as well newspaper coverage, and from aggregate data on import tariffs. Notwithstanding the different methodological approaches, all measures suggest that uncertainty about trade policy has recently shot up to levels not seen since the 1970s. We then assessed empirically the implications of unexpected increases in trade policy uncertainty on economic activity. Our firm-level estimates suggest that uncertainty about trade policy in 2018 only may have lowered aggregate U.S. investment by more than 1 percent. Our aggregate evidence based on VAR analysis points to even larger effects. Finally, we studied the transmission of trade policy uncertainty in a two-country general equilibrium model with heterogeneous firms and endogenous export decision. We find that both higher expected tariffs and increased uncertainty about future tariffs deters investment, as in the data. Our framework emphasizes the role of price rigidity (i.e. variable markups) and fixed costs of export as important mechanisms that amplify the effects of trade policy uncertainty. 


\section{References}

Alessandria, George and Horag Choi. 2007. "Do Sunk Costs of Exporting Matter for Net Export Dynamics?" The Quarterly Journal of Economics 122 (1):289-336. URL https://EconPapers . repec .org/RePEc: oup:qjecon:v:122:y:2007:i:1:p:289-336.

Alessandria, George, Horag Choi, Joseph P Kaboski, and Virgiliu Midrigan. 2015. "Microeconomic uncertainty, international trade, and aggregate fluctuations." Journal of Monetary Economics 69:20-38.

Altig, David, Nick Bloom, Steven Davis, Brent Meyer, and Nick Parker. 2019. "Tariff Worries and U.S. Business Investment, Take Two." Tech. rep., Atlanta Fed.

Backus, David K, Patrick J Kehoe, and Finn E Kydland. 1994. "Dynamics of the Trade Balance and the Terms of Trade: The J-Curve?" American Economic Review 84 (1):84-103. URL https://ideas.repec.org/a/aea/aecrev/v84y1994i1p84-103.html.

Baker, Scott R., Nicholas Bloom, and Steven J. Davis. 2016. "Measuring Economic Policy Uncertainty*." The Quarterly Journal of Economics 131 (4):1593. URL +http://dx.doi.org/10. 1093/qje/qjw024.

Barattieri, Alessandro, Matteo Cacciatore, and Fabio Ghironi. 2018. "Protectionism and the Business Cycle." NBER Working Papers 24353, National Bureau of Economic Research, Inc. URL https://ideas.repec.org/p/nbr/nberwo/24353.html.

Basu, Susanto and Brent Bundick. 2012. "Uncertainty Shocks in a Model of Effective Demand." NBER Working Papers 18420, National Bureau of Economic Research, Inc. URL https:// ideas.repec.org/p/nbr/nberwo/18420.html.

Bloom, Nicholas. 2009. "The impact of uncertainty shocks." econometrica 77 (3):623-685.

Bloom, Nicholas, Max Floetotto, Nir Jaimovich, Itay Saporta-Eksten, and Stephen J Terry. 2018. "Really uncertain business cycles." Econometrica 86 (3):1031-1065.

Born, Benjamin and Johannes Pfeifer. 2014. "Risk Matters: The Real Effects of Volatility Shocks: Comment." American Economic Review 104 (12):4231-39. URL http://www.aeaweb.org/ articles?id=10.1257/aer.104.12.4231.

Breusch, T. S. and A. R. Pagan. 1979. "A Simple Test for Heteroscedasticity and Random Coefficient Variation." Econometrica 47 (5):1287-1294. URL http://www.jstor.org/stable/1911963. 
Chari, V. V. 2018. "The Role of Uncertainty and Risk in Climate Change Economics." Staff Report 576, Federal Reserve Bank of Minneapolis. URL https://ideas.repec.org/p/fip/ fedmsr/576.html.

Christiano, Lawrence J., Martin Eichenbaum, and Charles L. Evans. 2005. "Nominal Rigidities and the Dynamic Effects of a Shock to Monetary Policy." Journal of Political Economy 113 (1):1-45. URL http://www. jstor.org/stable/10.1086/426038.

Clementi, Gian Luca and Berardino Palazzo. 2019. "Investment and the Cross-Section of Equity Returns." The Journal of Finance 74 (1):281-321. URL https://onlinelibrary.wiley.com/ doi/abs/10.1111/jofi.12730.

Corsetti, Giancarlo, Luca Dedola, and Sylvain Leduc. 2010. "Optimal monetary policy in open economies." In Handbook of monetary economics, vol. 3. Elsevier, 861-933.

Crowley, Meredith, Ning Meng, and Huasheng Song. 2018. "Tariff scares: Trade policy uncertainty and foreign market entry by Chinese firms." Journal of International Economics 114:96-115.

Del Negro, Marco, Marc P Giannoni, and Frank Schorfheide. 2015. "Inflation in the great recession and new keynesian models." American Economic Journal: Macroeconomics 7 (1):168-96.

Eberly, Janice, Sergio Rebelo, and Nicolas Vincent. 2012. "What explains the lagged-investment effect?" Journal of Monetary Economics 59 (4):370-380.

Erceg, Christopher, Andrea Prestipino, and Andrea Raffo. 2018. "The Macroeconomic Effect of Trade Policy." Tech. rep.

Fernald, John. 2012. "A Quarterly, Utilization-Adjusted Series on Total Factor Productivity." Working Paper Series 2012-19, Federal Reserve Bank of San Francisco. URL http://ideas. repec.org/p/fip/fedfwp/2012-19.html.

Fernandez-Villaverde, Jesus, Pablo Guerron-Quintana, Keith Kuester, and Juan Rubio-Ramrez. 2015. "Fiscal Volatility Shocks and Economic Activity." American Economic Review 105 (11):3352-84.

Gali, Jordi and Tommaso Monacelli. 2005. "Monetary policy and exchange rate volatility in a small open economy." The Review of Economic Studies 72 (3):707-734.

Gulen, Huseyin and Mihai Ion. 2015. "Policy Uncertainty and Corporate Investment." The Review of Financial Studies 29 (3):523-564. URL https://dx.doi.org/10.1093/rfs/hhv050.

Hamilton, James D. 2003. "What is an Oil Shock?" Journal of Econometrics 113 (2):363-398. URL http://www.sciencedirect.com/science/article/pii/S0304407602002075. 
Handley, Kyle and Nuno Limão. 2017. "Policy uncertainty, trade, and welfare: Theory and evidence for china and the united states." American Economic Review 107 (9):2731-83.

Hansen, Stephen, Michael McMahon, and Andrea Prat. 2017. "Transparency and deliberation within the FOMC: a computational linguistics approach." The Quarterly Journal of Economics $133(2): 801-870$.

Hassan, Tarek A., Stephan Hollander, Laurence van Lent, and Ahmed Tahoun. 2017. "Firm-Level Political Risk: Measurement and Effects." NBER Working Papers 24029, National Bureau of Economic Research, Inc. URL https://ideas.repec.org/p/nbr/nberwo/24029.html.

Irwin, Douglas A. 2013. "The Nixon shock after forty years: the import surcharge revisited." World Trade Review 12 (1):29-56.

Jaimovich, Nir and Sergio Rebelo. 2009. "Can news about the future drive the business cycle?" American Economic Review 99 (4):1097-1118.

Jorda, Oscar. 2005. "Estimation and Inference of Impulse Responses by Local Projections." American Economic Review 95 (1):161-182. URL http://www. aeaweb.org/articles?id=10.1257/ 0002828053828518.

Jurado, Kyle, Sydney C. Ludvigson, and Serena Ng. 2015. "Measuring Uncertainty." American Economic Review 105 (3):1177-1216. URL http://www.aeaweb.org/articles?id=10.1257/ aer. 20131193.

Mendoza, Enrique G. 1991. "Real business cycles in a small open economy." The American Economic Review :797-818.

Mendoza, Enrique G., Assaf Razin, and Linda L. Tesar. 1994. "Effective tax rates in macroeconomics: Cross-country estimates of tax rates on factor incomes and consumption." Journal of Monetary Economics 34 (3):297-323.

Ottonello, Pablo and Thomas Winberry. 2018. "Financial heterogeneity and the investment channel of monetary policy." Tech. rep., National Bureau of Economic Research.

Raffo, Andrea. 2008. "Net Exports, Consumption Volatility, and International Business Cycle Models." Journal of International Economics 75:14-29. URL https://www.sciencedirect. com/science/article/pii/S0022199607001158.

Ramey, Valerie A. 2011. "Identifying Government Spending Shocks: It's all in the Timing." Quarterly Journal of Economics 126 (1):1-50. URL http://ideas.repec.org/a/oup/qjecon/ v126y2011i1p1-50.html. 
Romer, Christina D. and David H. Romer. 2004. "A New Measure of Monetary Shocks: Derivation and Implications." American Economic Review 94 (4):1055-1084. URL http://www aeaweb. org/articles.php?doi=10.1257/0002828042002651.

Rotemberg, Julio J. 1982. "Sticky prices in the United States." Journal of Political Economy $90(6): 1187-1211$.

Steinberg, Joseph B. 2019. "Brexit and the macroeconomic impact of trade policy uncertainty." Journal of International Economics 117:175 - 195. URL http://www.sciencedirect.com/ science/article/pii/S0022199619300121.

White, Halbert. 1980. "A Heteroskedasticity-Consistent Covariance Matrix Estimator and a Direct Test for Heteroskedasticity." Econometrica 48 (4):817-838. URL http://www. jstor.org/ stable/1912934. 
Table 1: Tariff Rule: Parameter Estimates

\begin{tabular}{lccc}
\hline Parameter & Median & 5-th ptile & 95-th ptile \\
$\rho_{\tau}$ & 0.99 & 0.99 & 0.99 \\
$\sigma$ & -6.14 & -6.73 & -5.47 \\
$\rho_{\sigma}$ & 0.96 & 0.87 & 0.99 \\
$\eta$ & 0.37 & 0.29 & 0.47 \\
\hline
\end{tabular}

Note: The entries in the table denote the median, 5-th and 95-th percentiles of the posterior distribution of the parameters of the stochastic volatility model described in equations (1) and (2). 
Table 2: Trade Uncertainty and Industry Investment in 2018

\begin{tabular}{lcc}
\hline & $(1) \Delta \log K_{2018}-\Delta \log K_{2017}$ & $(2) \Delta \log K_{2018}-\Delta \log K_{2017}$ \\
\hline$\Delta S T P U_{j}$ in 2018 & $-1.565^{* *}$ & $-2.336^{* *}$ \\
& $(0.737)$ & $(0.983)$ \\
New Tariffs in 2018 & & 1.305 \\
& 46 & $(1.029)$ \\
Observations & 0.093 & 40 \\
R-squared & & 0.135 \\
\hline
\end{tabular}

Note: Standard errors in parenthesis. * and ** denote significance at the 10 and 5 percent level, respectively. Columns (1) to (2) regress change in industry investment (2018 vs 2017) against the standardized change in trade uncertainty at the industry level in 2018. Industries are grouped according to Fama and French 49-industries classification. We drop utilities, banks and financial institutions, as well as industries where we do not have data on new tariffs. 
Table 3: Orthogonality Between Tariff Volatility Shocks and Other External Shocks

\begin{tabular}{|c|c|c|c|c|}
\hline External Shocks & Correlation & (p-value) & Granger F-test & (p-value) \\
\hline Oil shocks ${ }^{\mathrm{a}}$ & -0.05 & $(0.58)$ & 0.84 & $(0.43)$ \\
\hline Monetary policy shocks ${ }^{\mathrm{b}}$ & -0.05 & $(0.70)$ & 0.78 & $(0.46)$ \\
\hline TFP growth shocks ${ }^{c}$ & -0.12 & $(0.11)$ & 2.71 & $(0.07)$ \\
\hline Defense spending shocks ${ }^{\mathrm{e}}$ & -0.01 & $(0.80)$ & 0.51 & $(0.60)$ \\
\hline Capital tax vol. shocks ${ }^{f}$ & -0.15 & $(0.05)$ & 0.62 & $(0.54)$ \\
\hline
\end{tabular}

Note: The entries in the table denote the pairwise correlations and Granger-causality tests between the trade policy uncertainty shock identified under the bivariate VAR with the news-based TPU index and a set of external instruments. The regressions underlying the pairwise Granger causality tests include a constant and two lags of each external instrument. Sample period for the TPU shocks is 1960:Q3 to 2018:Q3.

${ }^{\text {a }}$ Crude oil supply shock from Hamilton (2003).

${ }^{\mathrm{b}}$ Monetary policy shocks from Romer and Romer (2004); (1969:Q1-1984:Q4).

${ }^{\mathrm{c}}$ Residuals from a first-order autoregressive model of the log-difference in the utilization-adjusted total factor productivity; see Fernald (2012).

e Defense spending news shocks from Ramey (2011).

${ }^{\mathrm{f}}$ Capital tax volatility shocks from Fernandez-Villaverde et al. (2015). 
Table 4: Calibration

\begin{tabular}{lll}
\hline Parameter & Symbol & Value \\
\hline (a) Preferences & & \\
Discount Factor & $\beta$ & 0.99 \\
Risk Aversion & $\gamma_{R}$ & 2 \\
Habit & $b$ & 0.8 \\
Inverse Frisch Elasticity & $\mu$ & 1 \\
\hline
\end{tabular}

(b) Rigidities

Cost of wage adjustment $\quad \rho_{w} \quad 3317$

Cost of price adjustment $\quad \rho_{p} \quad 771$

Elasticity of labor demand $\quad \varepsilon_{w} \quad 10$

Elasticity of goods demand $\quad \varepsilon_{p} \quad 10$

(c) Technology - Retailers

Elasticity of substitution between varieties

$\varepsilon_{R} \quad 10$

(d) Technology - Wholesale Firms

Trade elasticity consumption goods $\quad \theta_{C} \quad 1.5$

Home bias for consumption goods $\quad \omega_{C} \quad 0.85$

Trade elasticity investment goods $\quad \theta_{I} \quad 1.5$

$\begin{array}{lll}\text { Home bias for investment goods } & \omega_{I} & 0.85\end{array}$

(e) Technology - Distributors

Elasticity of substitution between bundles $\varepsilon_{D} \quad 5$

(f) Technology - Intermediate Good Producers

Capital share $\quad \alpha$

Love-for-variety $\quad \lambda$

Investment adjustment cost $\quad r$

Fixed sunk export cost $\quad f(0) \quad 0.0148$

Fixed continuation export cost $\quad f(1) \quad 0.003$

\begin{tabular}{lll} 
Idiosyncratic TFP volatility & $\sigma_{z}$ & 0.5 \\
\hline \hline
\end{tabular}

(g) Policy Parameters

Coefficient on inflation

Coefficient on output gap

Inertia coefficient

$\alpha \quad 0.1$

$\lambda \quad 0.0$

10

(h) Technology process

Autoregressive coefficient $\quad M_{11}=M_{22} \quad 0.95$

Spillover coefficient $\quad M_{12}=M_{21} \quad 0.0$

Standard deviation $\quad \sigma_{Z} \quad 0.007$

Note: The entries in the table denote the calibrated parameters of the DSGE model. 
Figure 1: Trade Policy Uncertainty in Firms Earnings Calls

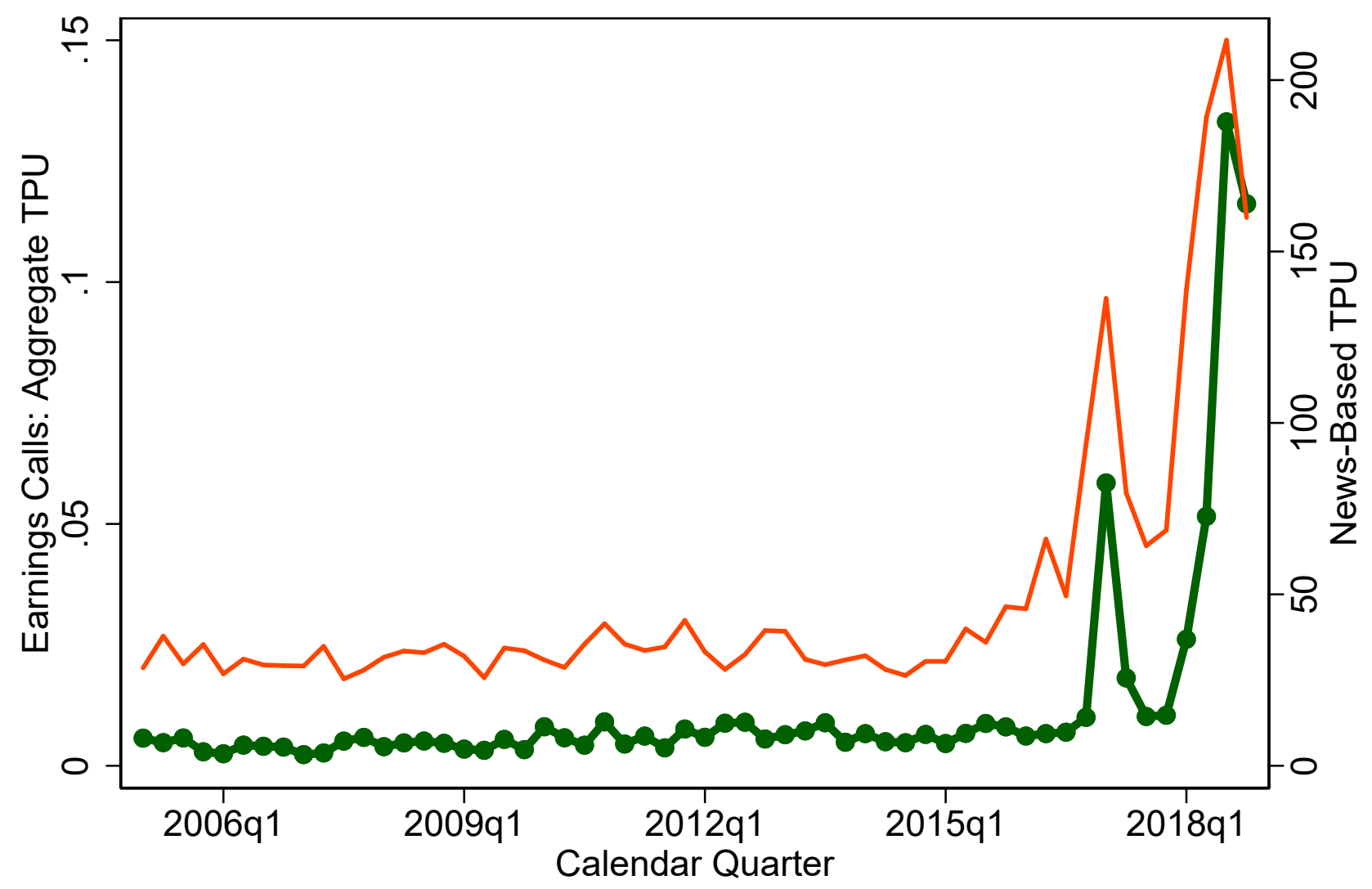

Earnings Calls: Aggregate TPU N News-Based TPU

NotE: In each quarter, aggregate $T P U$ from earnings calls measures the fraction of firms mentioning trade policy uncertainty in their earnings call. Newspaper Trade Uncertainty is the percent share of articles from seven major newspapers mentioning trade uncertainty. The latter series is indexed to 100 for an article share of 1 percent. 
Figure 2: Trade Policy Uncertainty By Industry over the Years
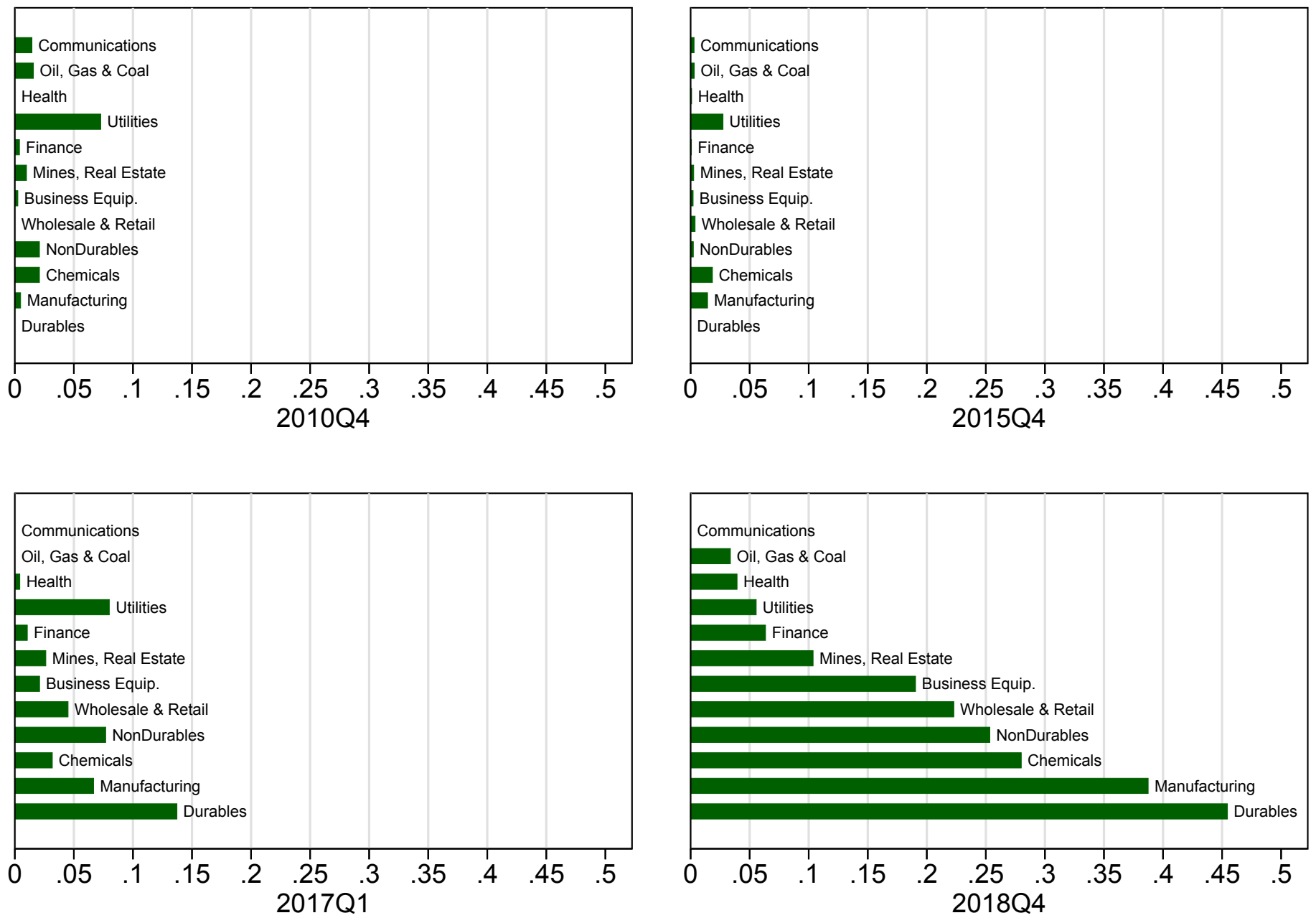

Note: Firms are grouped according to the Fama-French 12 industries classification. 


\section{Figure 3: List of Trade Policy Uncertainty Topics Covered in Earnings Calls}

\section{Topic 1}

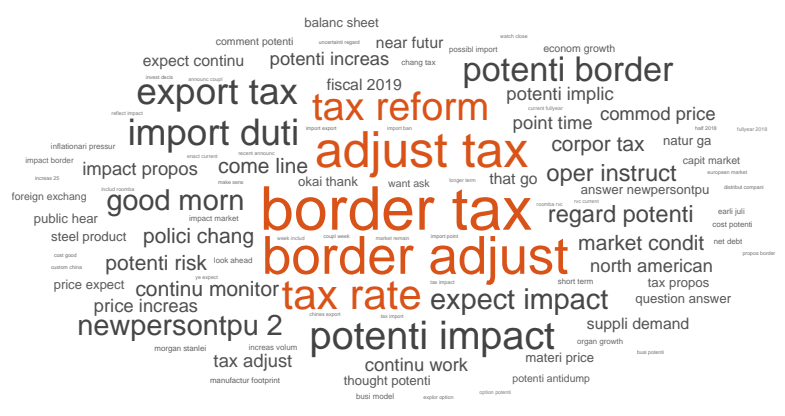

\section{Topic 3}

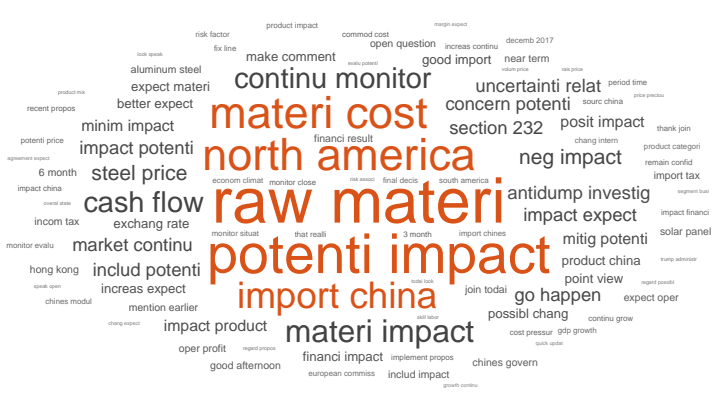

Topic 2
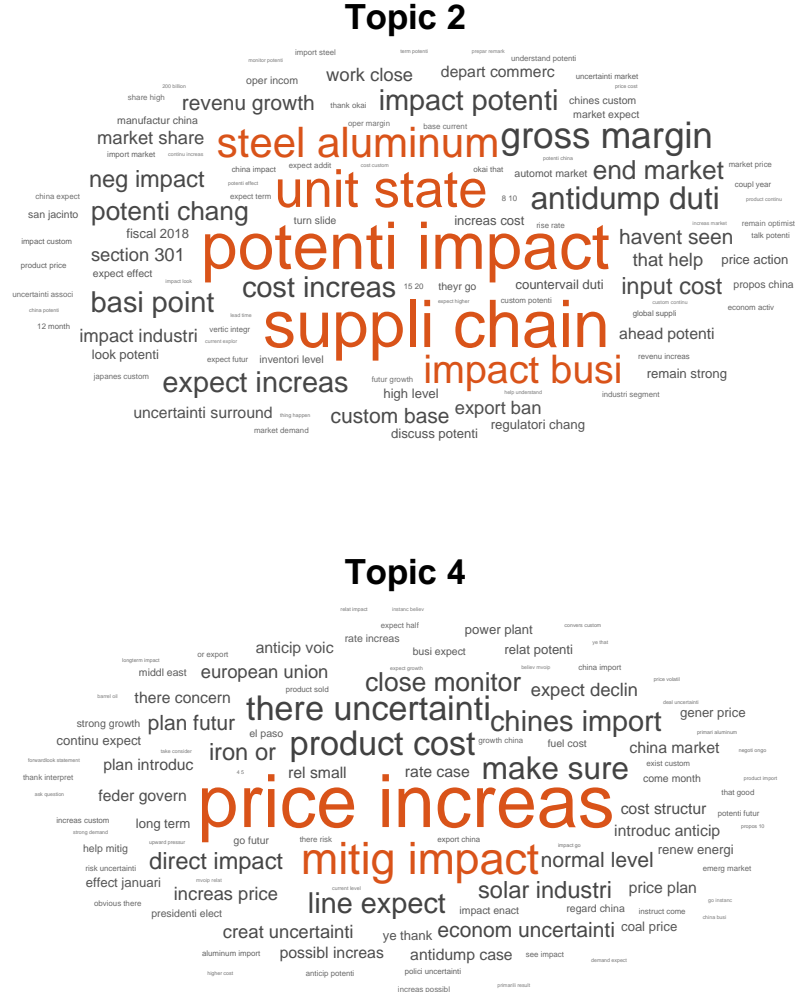

Note: LDA Analysis on Transcripts from All Years. Most Common Bigrams, Grouped by Topic. 
Figure 4: News-Based Index of Aggregate Trade Policy Uncertainty

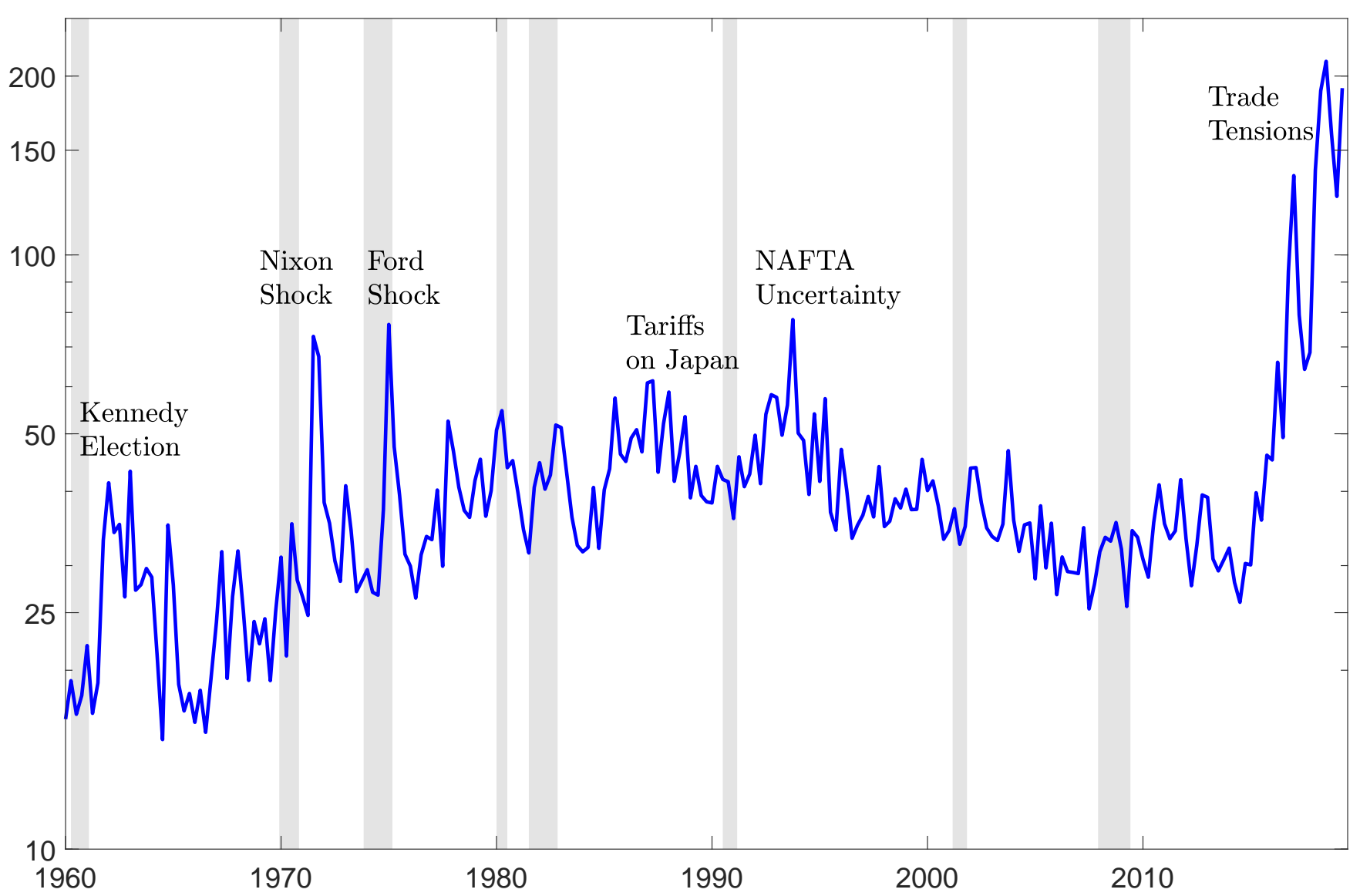

Note: Quarterly news-based trade policy uncertainty index extending through 2019Q2. A value of 100 indicates that one percent of all newspaper articles discuss trade policy uncertainty. The vertical gray areas represent NBER recession dates. The y-axis uses a log scale. 
Figure 5: Tariff Volatility Measure of Trade Policy Uncertainty

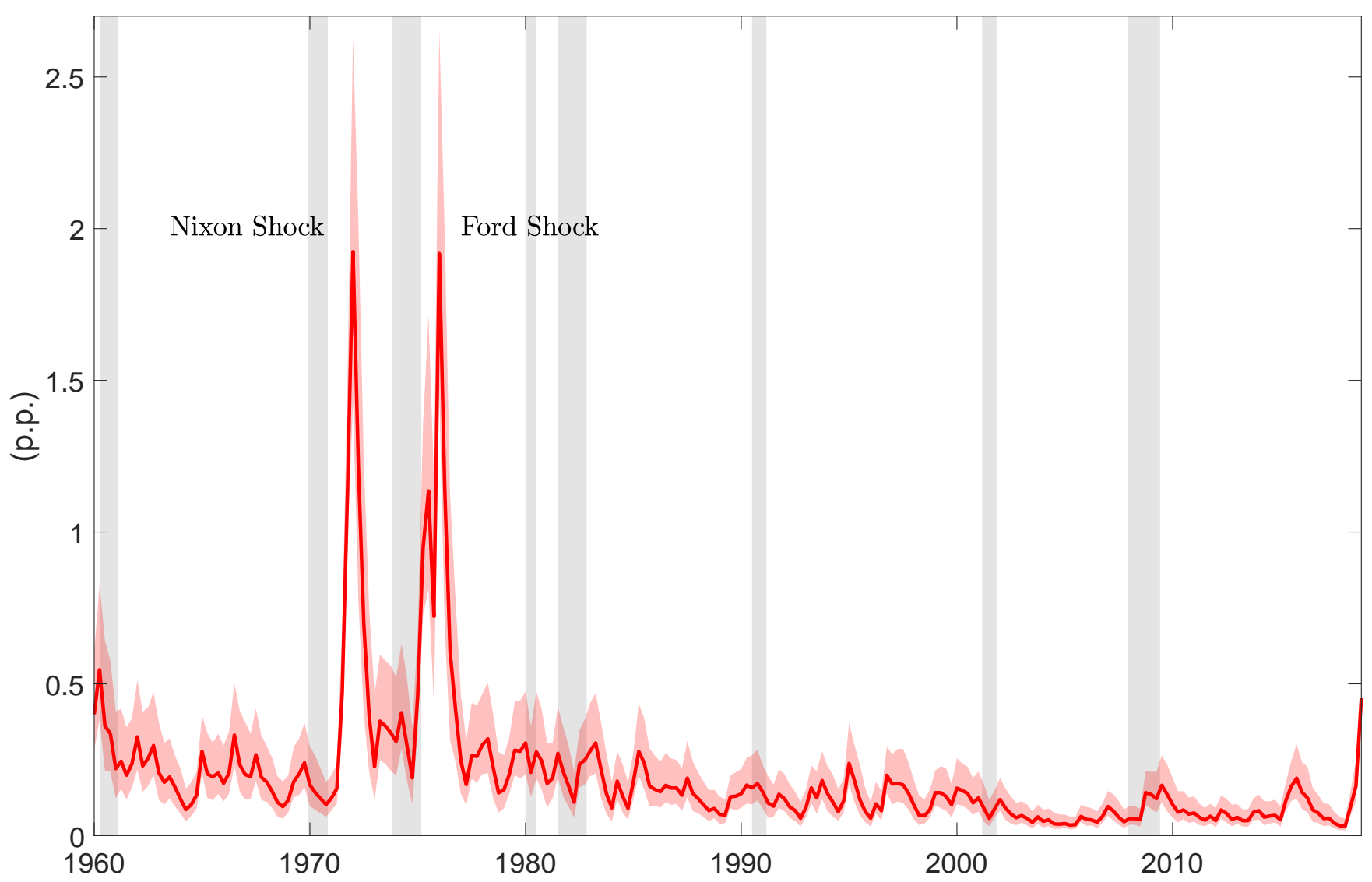

NotE: The red line plots the median of the filtered series of tariff volatility - expressed in percentage pointsestimated using a stochastic volatility model. The red shaded area surrounding the solid line represents the 90-percent point-wise credible sets, while the vertical gray areas represent NBER recession dates. 


\section{Figure 6: Response of Capital to Firm-Level TPU}

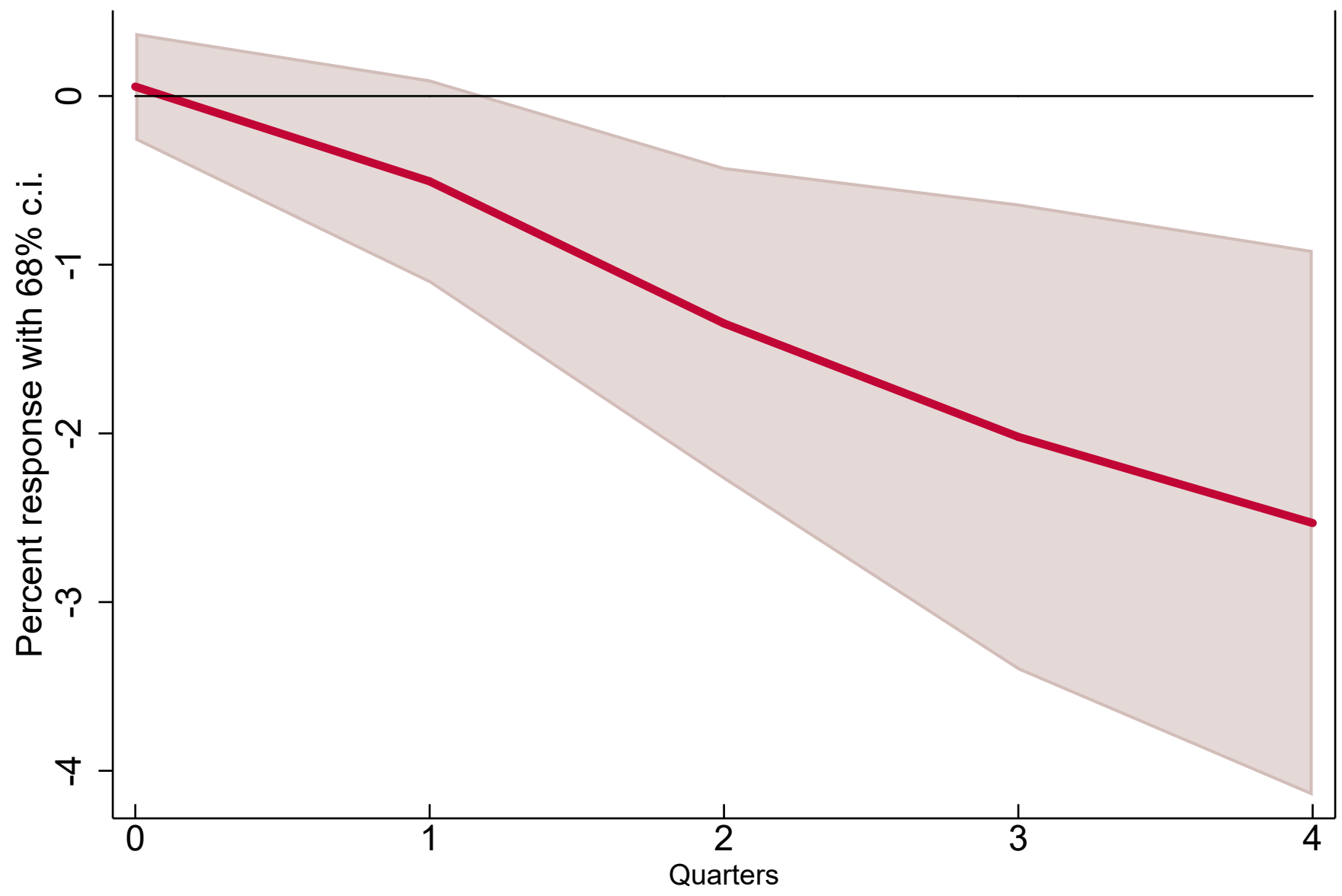

NotE: Firm-Level response of investment at different horizons following an increase in firm-level $T P U$ from 0 to 0.035 , its average value when $T P U$ is greater than 0 . The shaded areas denote 1 standard error confidence interval. Standard errors are two-way clustered by firm and quarter. 
Figure 7: Response of Capital to Firm-Level TPU: Additional Analysis
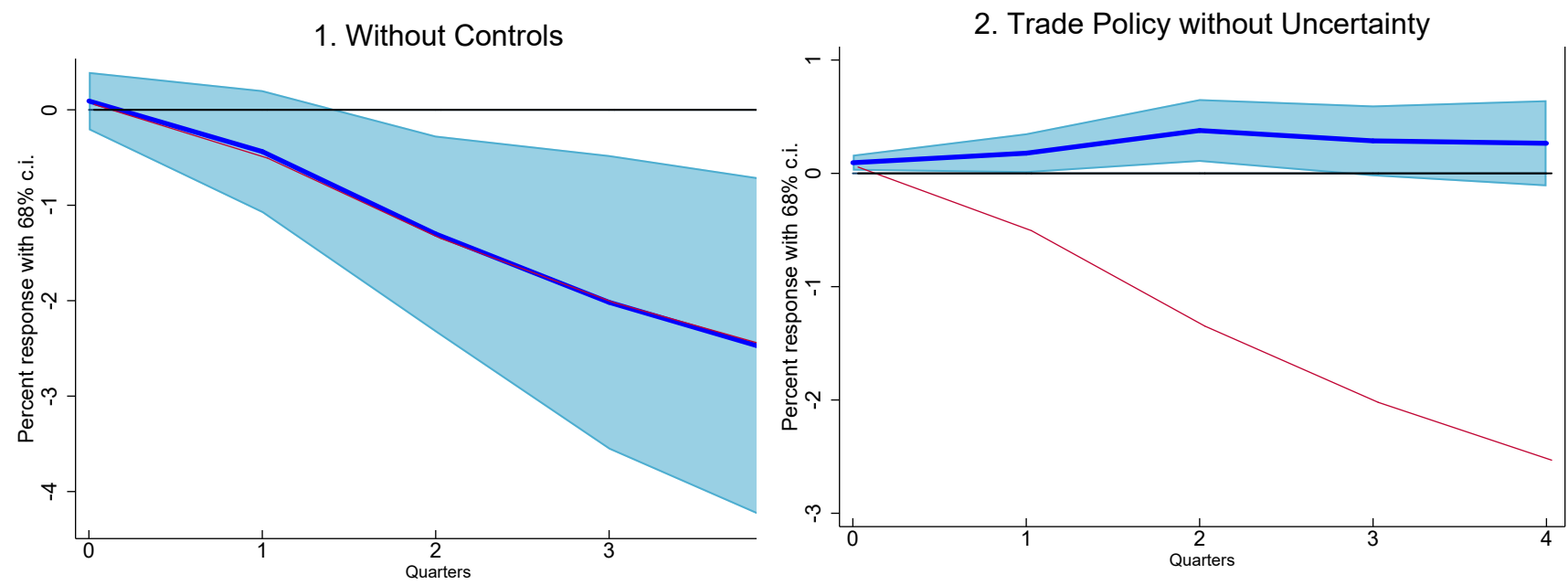

3. No Time Effects

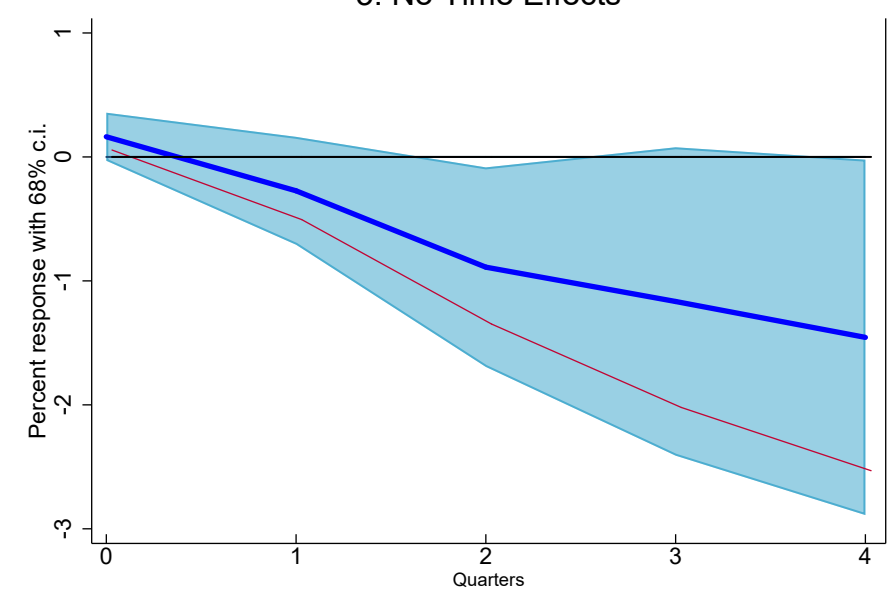

Note: Robustness. The thin red line is the response in the baseline experiment of Figure 6. Shaded areas denote 1 s.e. confidence interval. Standard errors are two-way clustered by firm and quarter. 
Figure 8: Investment And Industry TPU IN 2018

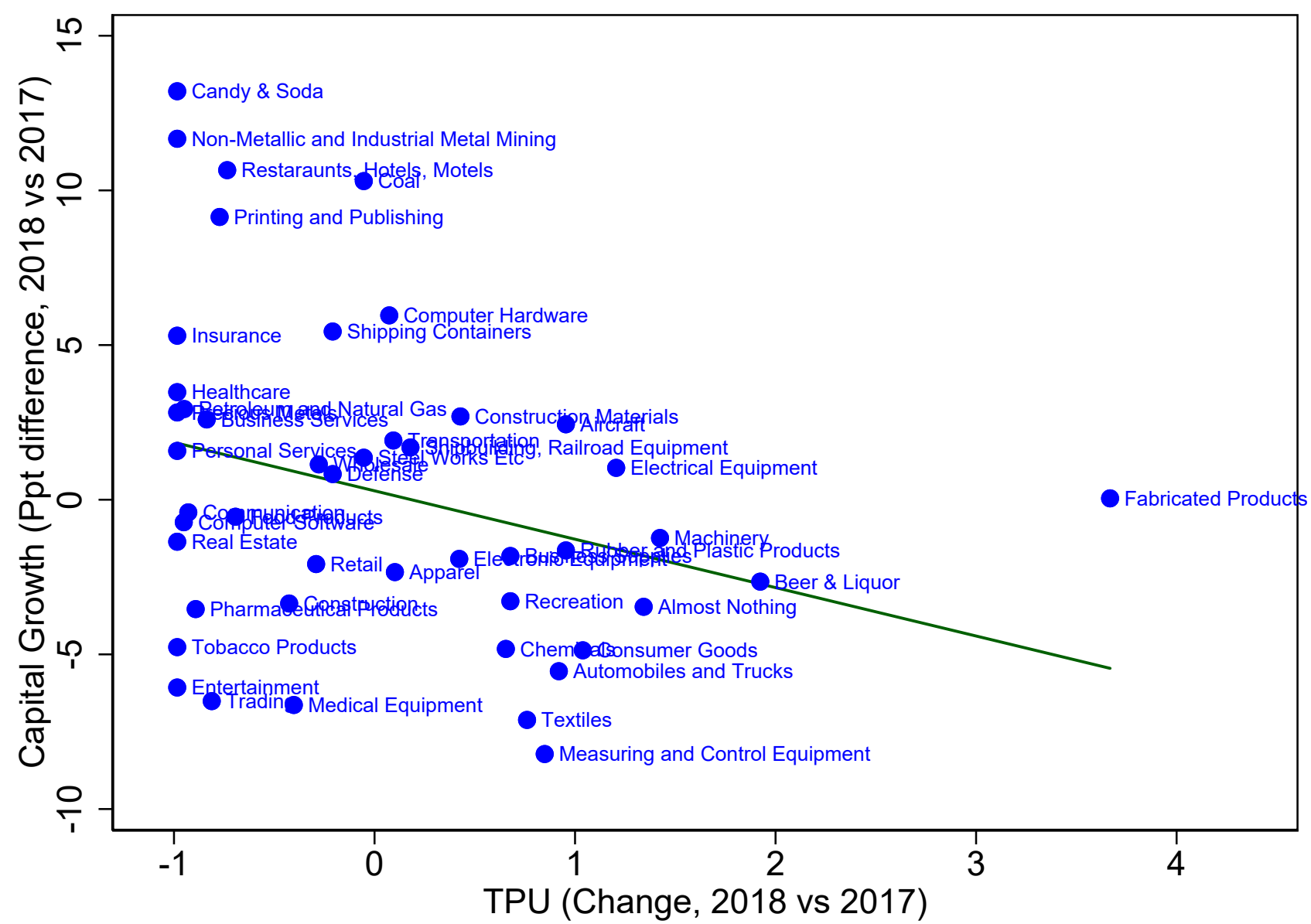

NotE: Change in TPU in 2018 and change in investment in 2018 across industries. 
Figure 9: The Investment Effects of TPU and Tariff Volatility Shocks
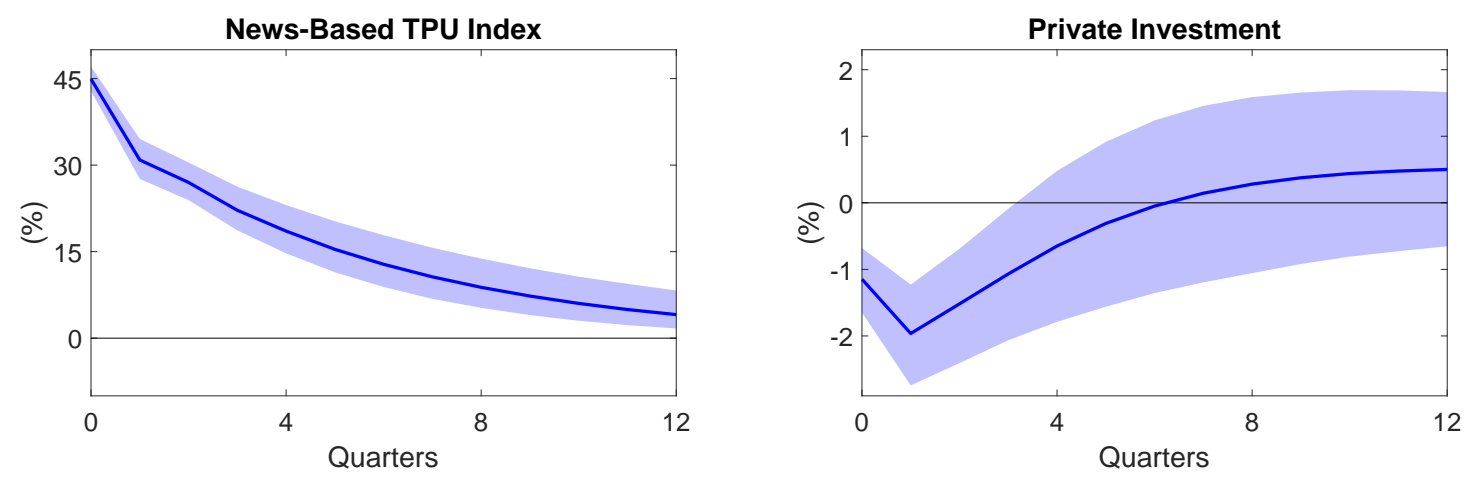

(a) Bivariate VAR with News-Based TPU
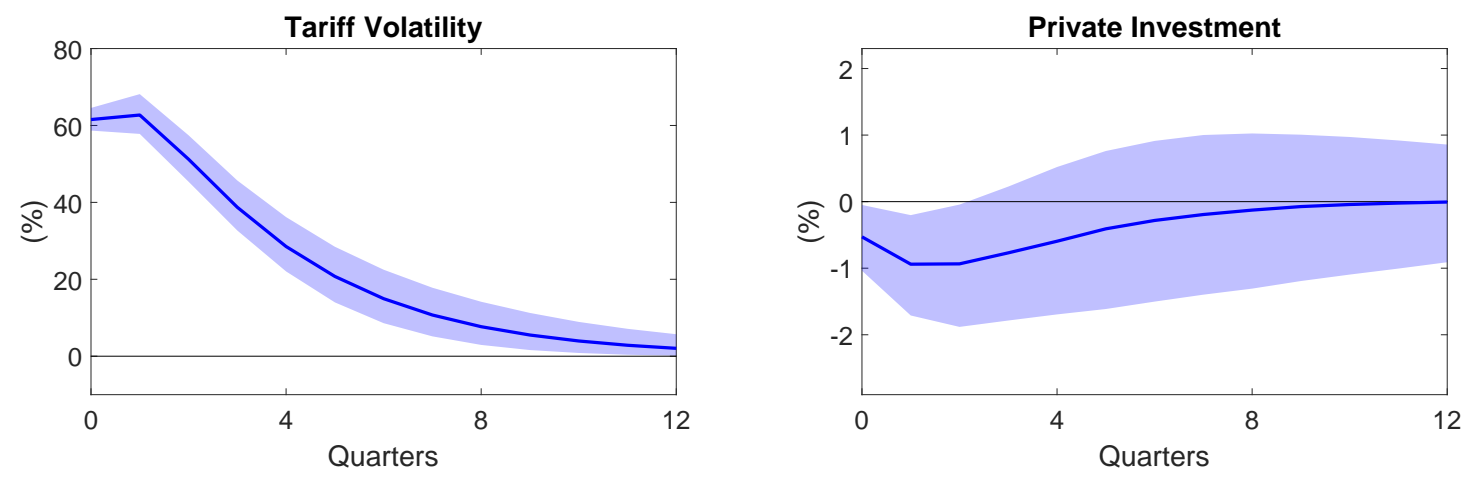

(b) Bivariate VAR with TarifF Volatility
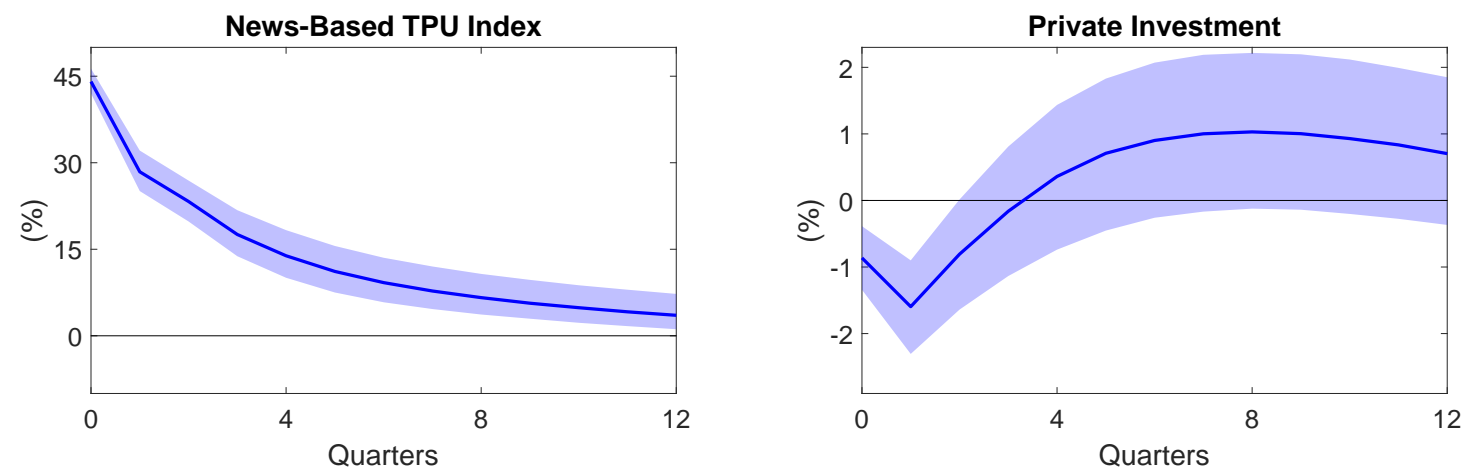

(c) Multivariate VAR with News-Based TPU

Note: The solid lines depict median responses of trade uncertainty indicators and private investment to a trade policy uncertainty shock of size two standard deviations. The VAR model is estimated on quarterly data from 1960 to 2018. The shaded bands represent the 70-percent point-wise credible sets. 
Figure 10: Impulse Responses to News And Uncertainty Shocks.
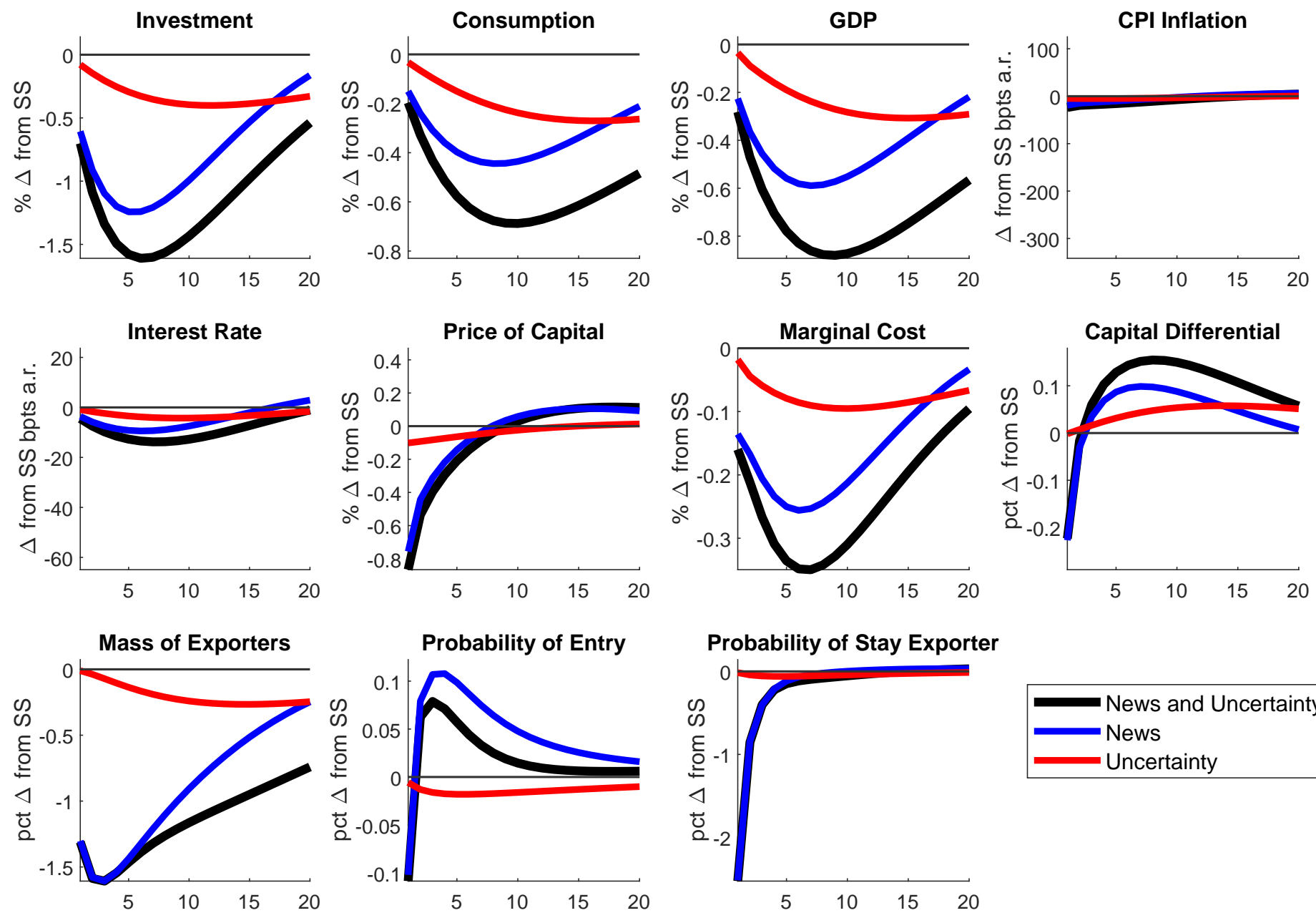

Note: Model Impulse Responses to News Shocks and Uncertainty Shocks. The horizontal axis measures quarters since the shock. 
Figure 11: Impact of News about Future TARIffs.
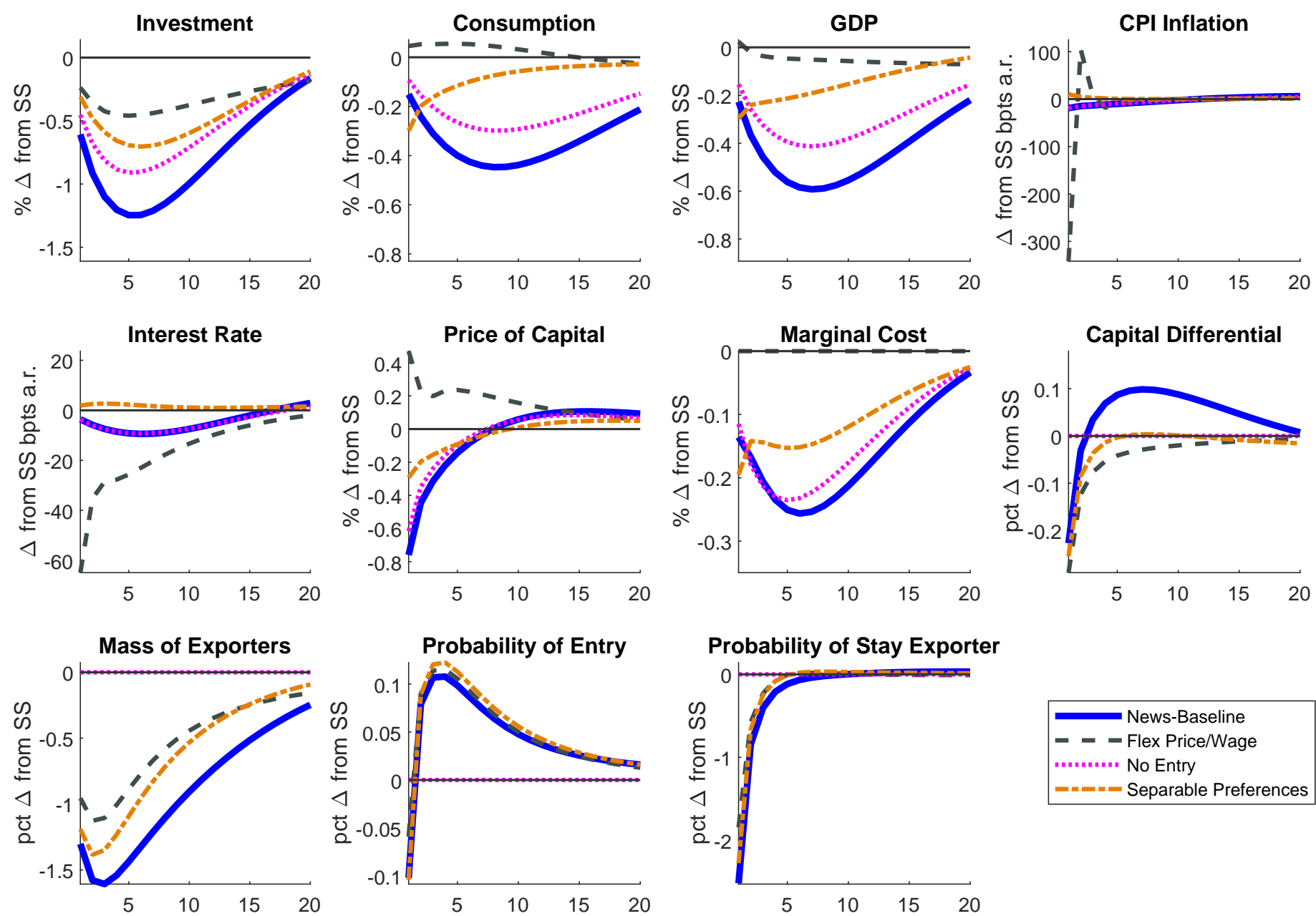

Note: Robustness Analysis: Model Impulse Responses to News Shocks. The horizontal axis measures quarters since the shock. 
Figure 12: Impact of Higher Uncertainty about Future TARiffs.
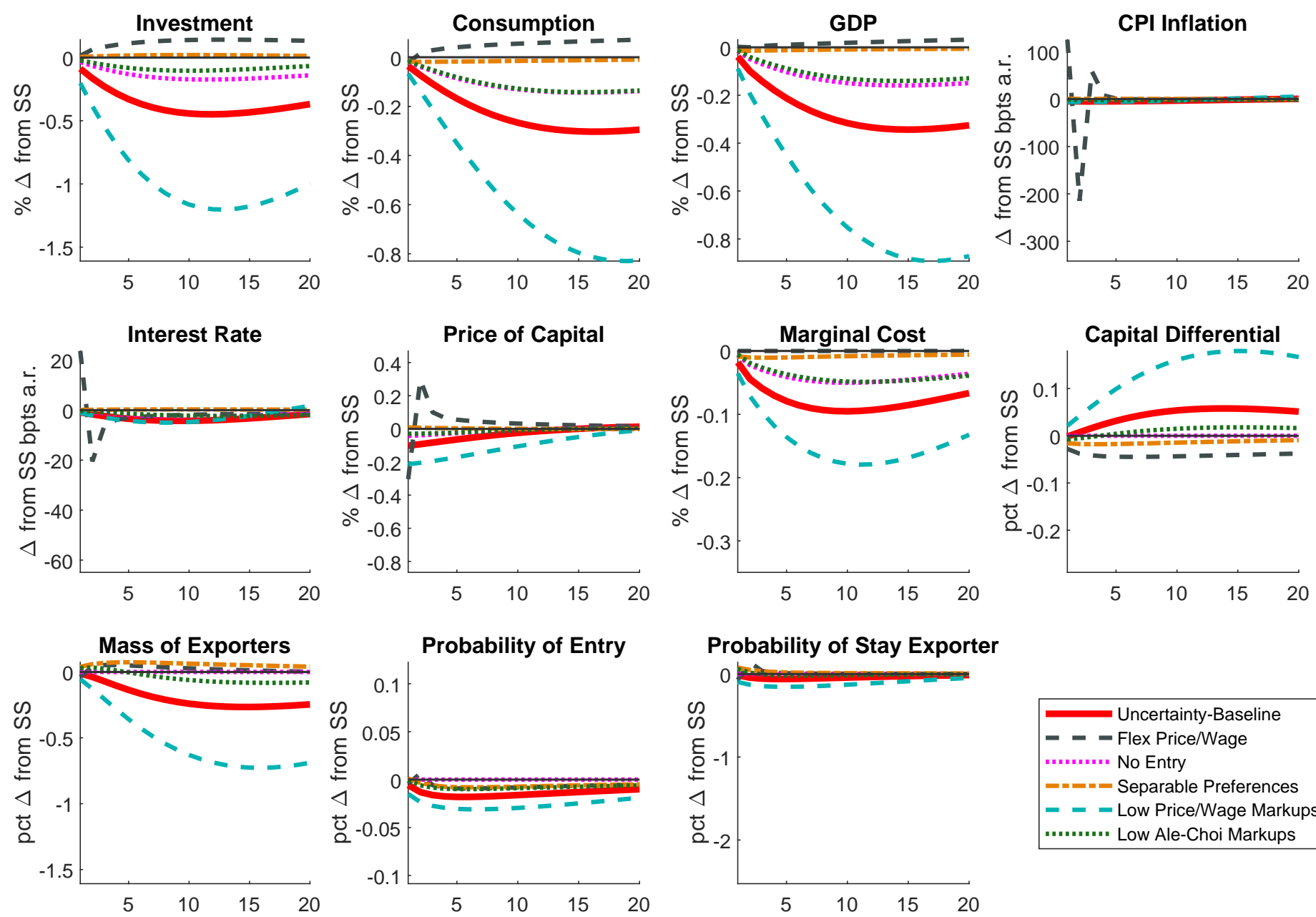

Note: Robustness Analysis: Model Impulse Responses to Uncertainty Shocks. The horizontal axis measures quarters since the shock. 


\section{Appendix}

\section{A.1 Description of Firm-Level and Industry Data}

Our firm-level data source is the Compustat North America database. Our key variables are investment, cash flows, and Tobin's Q, which we construct following standard approaches to Compustat data in the literature (e.g. Ottonello and Winberry (2018)). Compustat variables names are shown in all capital letters.

1. Data preparation. We consider only firms with headquarters located in the United States (Compustat variable LOC is "USA"). We next drop observations with non-positive quarterly capital expenditures (CAPXY), total assets (ATQ) less than $\$ 1$ million in chained 2009 dollars, and acquisitions (AQCY) are greater than 5\% of assets. Lastly we drop observations where net property, plant, and equipment (PPENTQ) decreases and then increases (or vice versa) more than fifty percent between two successive quarters.

2. Industries included. We exclude firms in the utilities, banking, and finance sectors (firms with a 4-digit Standard Industrial Classification (SIC) code in the ranges 4900-4999 and 6000-6299). We also restrict the sample to sectors trading in agricultural, mining, and manufacturing goods (3-digit NAICS codes in the ranges 111-115, 211-212, and 311-339), omitting wholesale and service industries. These sectors are those for which we have complete data to construct our measure of openness, but they are also those with higher instances of TPU Our final industry selection includes roughly half the original sample Compustat firms.

3. Investment. For our measure of investment $\log k_{i, t+h}-\log k_{i, t-1}$ (with $h \geq 0$ ) we define a firm's capital stock $k_{i, t}$ as gross property, plant, and equipment (PPEGTQ) in the first period for which there is data are available. Thereafter we use PPENTQ.

4. Tobin's Q. We define Tobin's Q as the ratio of a firm's total market value to its total asset value, where market value is the book value of assets plus the market value of stock (price at close (PRCCQ) * common shares CSHQQ)) less the book value of stock (CEQ). The final

measure is thus equal to $\frac{A T Q+(P R C C Q * C S H O Q)-C E Q Q}{A T Q}$. We winsorize the variable at the 1 st and 99th percentile.

5. Cash flows. We measure cash flows using the ratio of cash and short-term investments (CHEQ) to beginning-of-period property, plant, and equipment, which is the first lag of PPENTQ in our sample. We winsorize the variable at the 1st and 99th percentile.

6. Openness. Openness is defined at the 3-digit level of the North American Industry Classification System (NAICS). We use a standard measure equal to the ratio of an industry's gross output to usage, where usage is gross output plus imports less exports. Using gross output by industry from the Bureau of Economic Analysis' Industry Economic Accounts Data and exports/imports by industry from the U.S. Census Bureau's U.S. International Trade and Goods and Services report (FT900). 


\section{A.2 Stochastic Volatility Model: Robustness}

In our bechmark empirical specification, we posit that tariffs follow an autoregressive process with (auturegressive) stochastic volatility. Table 1A compares our benchmark estimates to those obtained from two alternative models. Model 1 includes feedback from lagged values of detrended output and U.S. federal public debt. This approach follows closely the fiscal volatility rule adopted in Fernandez-Villaverde et al. (2015) and is meant to capture the idea that the state of the business cycle and the level of debt may influence behavior of government instruments, including tariffs. Model 2 allows for feedback from lagged values of detrended output and the U.S. net foreign asset position. This rule incorporates the idea that developments in the external position of the United States, approximated by the net foreign asset position, may also affect the setting of tariffs.

Table 1A. Tariff Rule: Robustness

\begin{tabular}{|c|c|c|c|}
\hline & Benchmark & Model 1 & Model 2 \\
\hline$\rho_{\tau}$ & $\begin{array}{c}0.99 \\
{[0.99 ; 0.99]}\end{array}$ & $\begin{array}{c}0.99 \\
{[0.99 ; 0.99]}\end{array}$ & $\begin{array}{c}0.98 \\
{[0.97 ; 0.99]}\end{array}$ \\
\hline$\sigma$ & $\begin{array}{c}-6.14 \\
{[-6.73 ;-5.47]}\end{array}$ & $\begin{array}{c}-6.35 \\
{[-6.84 ;-5.76]}\end{array}$ & $\begin{array}{c}-6.05 \\
{[-6.32 ;-5.78]}\end{array}$ \\
\hline$\rho_{\sigma}$ & $\begin{array}{c}0.96 \\
{[0.87 ; 0.99]}\end{array}$ & $\begin{array}{c}0.93 \\
{[0.85 ; 0.97]}\end{array}$ & $\begin{array}{c}0.85 \\
{[0.72 ; 0.92]}\end{array}$ \\
\hline$\eta$ & $\begin{array}{c}0.37 \\
{[0.29 ; 0.47]}\end{array}$ & $\begin{array}{c}0.39 \\
{[0.32 ; 0.49]}\end{array}$ & $\begin{array}{c}0.37 \\
{[0.29 ; 0.47]}\end{array}$ \\
\hline
\end{tabular}

Note. Estimates refer to posterior medians. Numbers in brackets are the 90 percent probability interval.

Overall, we find that the inclusion of macroeconomic feedbacks does not greatly affect the estimation of the tariff rule parameters. The average standard deviation of tariffs varies from $100 * \exp (-6.14)=0.24$ percentage point in the bechmark model to 0.18 (Model 1) and 0.24 (Model 2). Model 2 also seems to have a slightly lower volatility persistence than our benchmark model (0.85 vs 0.96$)$. A one-standard deviation shock to tariff volatility increases the volatility by about 10 basis points in all models. 


\section{A.3 Additional Tables}

Table A.1: Episodes of High Aggregate Trade Policy Uncertainty

\begin{tabular}{|c|c|c|c|}
\hline U.S. Administration & Policy Action & Quarter & Quotes or Additional Narrative Material \\
\hline President Kennedy & $\begin{array}{l}\text { Trade Negotia- } \\
\text { tions }\end{array}$ & 1960q1 & $\begin{array}{l}\text { "This is the year to decide. The Reciprocal Trade Act is expiring. We need a new law-a } \\
\text { wholly new approach - a bold new instrument of American trade policy. Our decision } \\
\text { could well affect the economic growth of our Nation for a generation to come." }\end{array}$ \\
\hline President Nixon & Tariff Increase & $1971 q 4$ & $\begin{array}{l}\text { "I am taking one further step to protect the dollar, to improve our balance of payments, } \\
\text { and to increase jobs for Americans. As a temporary measure, I am today imposing an } \\
\text { additional tax of } 10 \text { percent on goods imported into the United States. This is a better } \\
\text { solution for international trade than direct controls on the amount of imports. This } \\
\text { import tax is a temporary action... When the unfair treatment is ended, the import tax } \\
\text { will end as well." }\end{array}$ \\
\hline President Ford & Tariff Increase & $1975 \mathrm{q} 2$ & $\begin{array}{l}\text { "...we need immediate action to cut imports. ... Therefore, I am using Presidential powers } \\
\text { to raise the fee on all imported crude oil and petroleum products...To that end, I am re- } \\
\text { questing the Congress to act within } 90 \text { days on a more comprehensive energy tax program. } \\
\text { It includes: excise taxes and import fees totaling } \$ 2 \text { per barrel on product imports and on } \\
\text { all crude oil; deregulation of new natural gas and enactment of a natural gas excise tax...I } \\
\text { am prepared to use Presidential authority to limit imports, as necessary, to guarantee } \\
\text { success...To provide the critical stability for our domestic energy production in the face of } \\
\text { world price uncertainty, I will request legislation to authorize and require tariffs, import } \\
\text { quotas, or price floors to protect our energy prices at levels which will achieve energy } \\
\text { independence." }\end{array}$ \\
\hline
\end{tabular}

NOTE: Narrative analysis of major increases in aggregate trade policy uncertainty. 


\section{Table A.2: Selected Quotes from Earnings Call Transcripts Mentioning Trade Policy Uncertainty}

\begin{tabular}{|c|c|c|c|c|c|}
\hline \multirow{2}{*}{$\begin{array}{l}\text { Company Name } \\
\text { SUNPOWER }\end{array}$} & \multirow{2}{*}{$\begin{array}{l}\text { Sector } \\
\text { Electronic } \\
\text { Equipment }\end{array}$} & \multicolumn{4}{|c|}{ Quarter $\Delta K_{+1}$ TPU Selected Quotes Mentioning Trade Policy Uncertainty } \\
\hline & & $2017 \mathrm{q} 3$ & -14.6 & 2 & $\begin{array}{l}\text { In September, the ITC is scheduled to decide whether to recommend the imposition of } \\
\text { import tariffs or quotas on solar panels and to subsequently propose specific remedies } \\
\text { in November. [...] the requested remedies could significantly impact the U.S. solar } \\
\text { market, imposing a direct burden on manufacturers }\end{array}$ \\
\hline $\begin{array}{l}\text { BUILDERS } \\
\text { FIRSTSOURCE }\end{array}$ & $\begin{array}{l}\text { Construction } \\
\text { Materials }\end{array}$ & $2017 \mathrm{q} 2$ & -11.0 & 3 & $\begin{array}{l}\text { Q: }[\ldots] \text { on the lumber import tariff how have you handled }[\ldots] \text { the tariff and the price } \\
\text { volatility? }[\ldots] \text { A: Yes, could be a slight headwind to working capital. }\end{array}$ \\
\hline $\begin{array}{l}\text { RENEWABLE } \\
\text { ENERGY GROUP }\end{array}$ & $\begin{array}{l}\text { Petroleum and } \\
\text { Natural Gas }\end{array}$ & $2017 q 3$ & -9.5 & 2 & $\begin{array}{l}\text { Q: I wanted to ask thoughts around the postponed EU vote last week around Ar- } \\
\text { gentina's challenge to the EU antidumping duties there and if there is the potential for } \\
\text { gallons to potentially flow back into the EU from Argentina and Indonesia. A: Well, } \\
\text { we were certainly watching that as it affects our European operation margins... }\end{array}$ \\
\hline WEYERHAEUSER & $\begin{array}{l}\text { Construction } \\
\text { Materials }\end{array}$ & $2017 \mathrm{q} 3$ & -5.7 & 2 & $\begin{array}{l}\text { On June } 26 \text {, the Department of Commerce announced preliminary antidumping duties } \\
\text { on Canadian lumber producers. For most producers, the duty will be approximately } 7 \\
\text { percent and will also be assessed retroactively. [...] The government will continue its } \\
\text { investigation through the remainder of the year, as the Department of Commerce and } \\
\text { International Trade Commission collect and evaluate additional information in support } \\
\text { of final determinations of the duties and a level of material injury to U.S. producers. } \\
\text { These determinations are expected later this year. The U.S. coalition continues to work } \\
\text { closely with the Department of Commerce, and we remain hopeful we will be able to } \\
\text { reach a quota-based agreement. }\end{array}$ \\
\hline $\begin{array}{l}\text { RENEWABLE } \\
\text { ENERGY GROUP }\end{array}$ & $\begin{array}{l}\text { Petroleum and } \\
\text { Natural Gas }\end{array}$ & $2017 q 4$ & -6.2 & 2 & $\begin{array}{l}\text { Finally, antidumping determinations are expected in early January. Based on these } \\
\text { very positive preliminary rulings, we are confident that the final decision will be sup- } \\
\text { portive of domestic biodiesel production. }\end{array}$ \\
\hline $\begin{array}{l}\text { BROADWIND } \\
\text { ENERGY }\end{array}$ & Machinery & $2017 \mathrm{q} 3$ & -3.1 & 3 & $\begin{array}{l}\text { Q. Have you done any type of quantitative impact or assessment on [...] the towers } \\
\text { business, but potentially all of your segments, if such a [steel] tariff was put into place? } \\
\text { A. It's not - would not be a good thing, because of the steel that we consume in our } \\
\text { businesses. }\end{array}$ \\
\hline $\begin{array}{l}\text { RENEWABLE } \\
\text { ENERGY GROUP }\end{array}$ & $\begin{array}{l}\text { Petroleum and } \\
\text { Natural Gas }\end{array}$ & $2017 \mathrm{q} 2$ & -5.4 & 2 & $\begin{array}{l}{[\ldots] \text { Our industry trade group took on an initiative to pull domestic producers together }} \\
\text { in a coalition to just ask for a fair trade, a level playing field and countervailing duties } \\
\text { and antidumping against } 2 \text { countries. }\end{array}$ \\
\hline $\begin{array}{l}\text { MOHAWK } \\
\text { INDUSTRIES }\end{array}$ & Textiles & $2017 \mathrm{q} 2$ & -2.9 & 2 & $\begin{array}{l}\text { Q. Great. Any potential impact from the proposed Canadian tariff? A. Listen, if you } \\
\text { can tell me what the proposals will look like, I'll decide what it is. }\end{array}$ \\
\hline CABOT CORP & Chemicals & $2016 \mathrm{q} 2$ & -2.3 & 2 & $\begin{array}{l}\text { There is some concern about [inventories] - with anti-dumping duties against truck } \\
\text { tires out of China that, that could cause the same phenomenon to happen again. But } \\
\text { I think we are probably closer to natural inventory levels than certainly we were over } \\
\text { the last } 18 \text { months or so as those passenger car duties were implemented. }\end{array}$ \\
\hline INTL PAPER & Business Supplies & $2015 \mathrm{q} 2$ & -2.1 & 2 & $\begin{array}{l}\text { Q. ... Just turning to Brazil. [...] Potentially, higher taxes and tariffs on energy usage. } \\
\text { A. I mean, the Brazil packaging business is in the same market, experiencing the same } \\
\text { dynamics as our paper business. So, demand has been a challenge. }\end{array}$ \\
\hline FORD MOTOR & $\begin{array}{l}\text { Automobiles and } \\
\text { Trucks }\end{array}$ & $2017 \mathrm{q} 1$ & -.8 & 2 & $\begin{array}{l}\text { Q. You clearly mentioned the prospects of an import tariff. There is [...] probability of a } \\
\text { border tax adjustment, and if that doesn't happen, then we're just going to see import } \\
\text { tariffs. A. [...] whether it's a border tax or border adjustment, as Bob mentioned, this } \\
\text { is a multifaceted blueprint that's out there. }\end{array}$ \\
\hline
\end{tabular}

NotE: Selected mentions of firm-level trade policy uncertainty extracted from the earnings call which are followed by a decline in firm-level investment in the next calendar quarter. The $\Delta K$ column indicates the percent change in the firm's capital stock in the calendar quarter subsequent to the mention. The TPU column lists the total number of mentions of trade policy uncertainty in the transcript of the earnings call. 


\section{A.4 Additional Figures}

Figure A.1: Comparison with Hassan et AL. (2017)

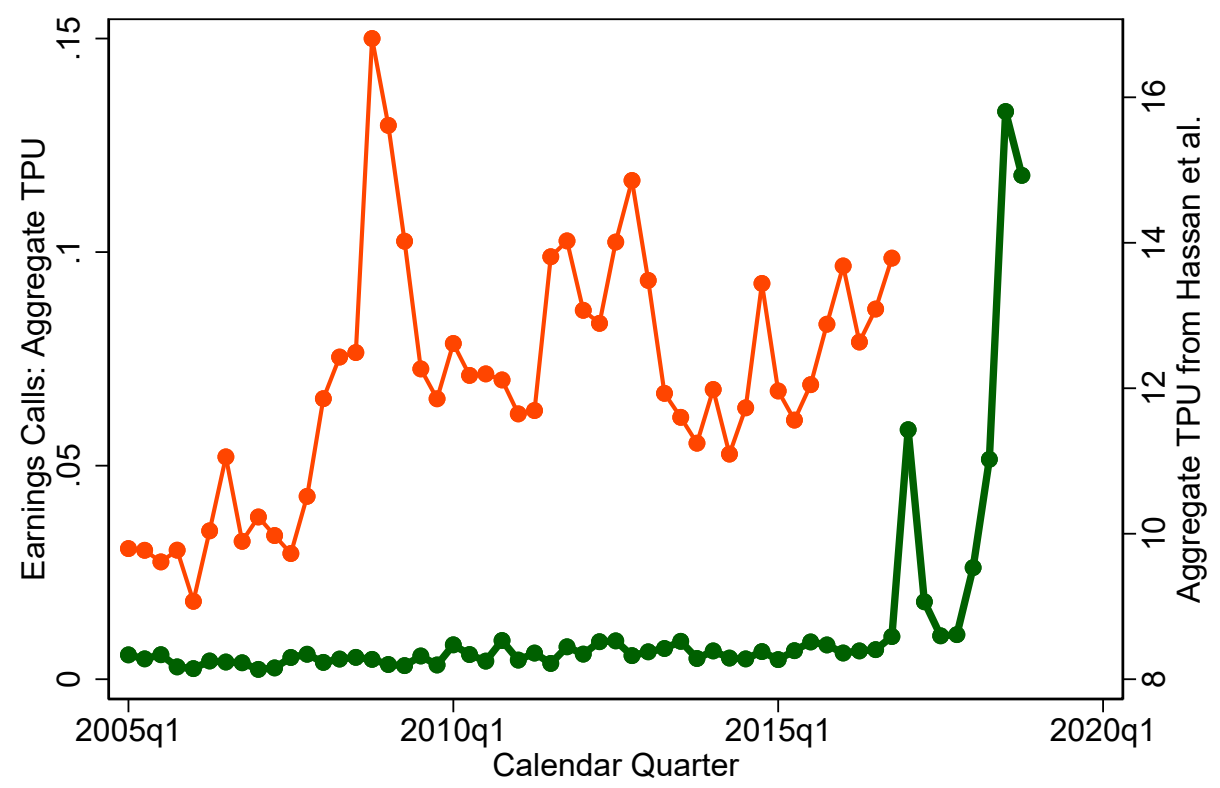

Earnings Calls: Aggregate TPU ___ Aggregate TPU from Hassan et al.

Note: Aggregate TPU from earnings calls in this paper and in Hassan et al. (2017)

Figure A.2: Comparison with Baker, Bloom, And Davis (2016)

TPU: Caldara et al. (2019) vs. Baker et al. (2016)

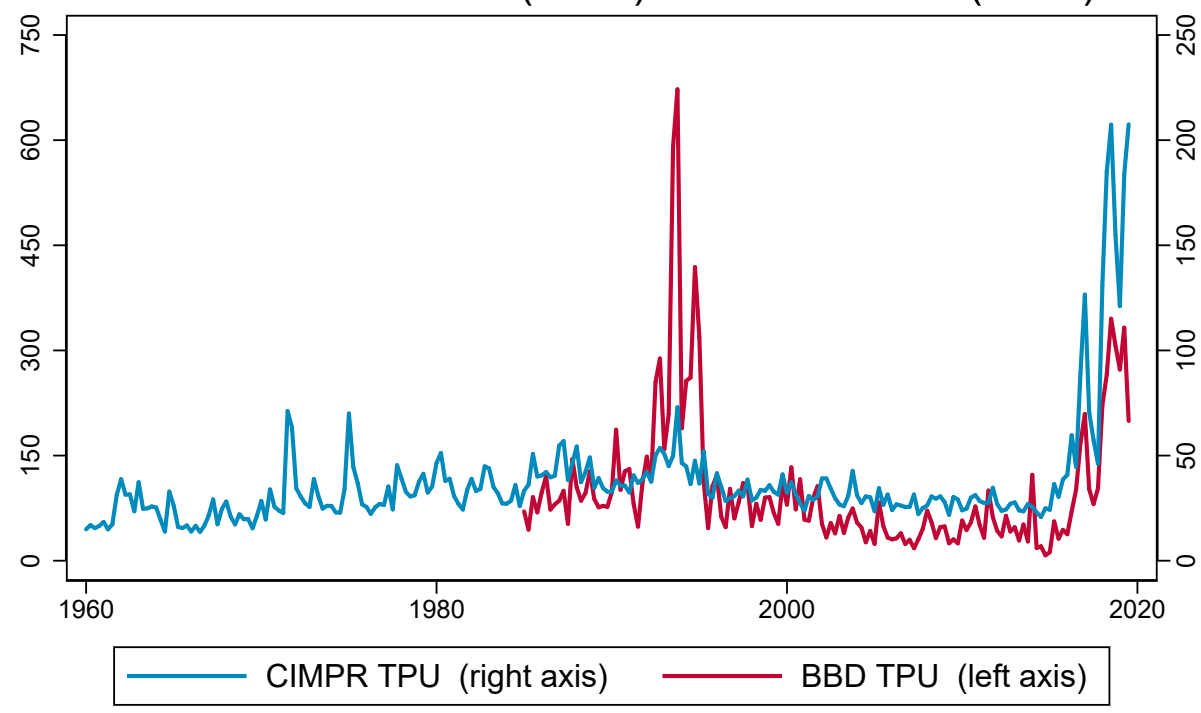

Note: News-based TPU in this paper and in Baker, Bloom, and Davis (2016). 